\title{
Hedgehog regulation of epithelial cell state and morphogenesis in the larynx
}

Janani Ramachandran ${ }^{1}$, Weiqiang Zhou², Anna E. Bardenhagen ${ }^{1}$, Talia Nasr ${ }^{3,4}$, Aaron M. Zorn ${ }^{3,4}$, Hongkai $\mathrm{Ji}^{2}$ and Steven A. Vokes ${ }^{1^{*}}$

${ }^{1}$ Department of Molecular Biosciences, University of Texas at Austin, $100 \mathrm{E}$ 24th Street Stop A5000, Austin, TX 78712 USA

${ }^{2}$ Department of Biostatistics, Johns Hopkins Bloomberg School of Public Health, 615 North Wolfe Street, Room E3638, Baltimore, MD 21205, USA

${ }^{3}$ Center for Stem Cell and Organoid Medicine (CuSTOM), Division of Developmental Biology, and Perinatal Institute, Cincinnati Children's Hospital Medical Center, Cincinnati, OH 45219, USA

${ }^{4}$ Department of Pediatrics, University of Cincinnati College of Medicine, Cincinnati, $\mathrm{OH}$ 45219, USA

"Corresponding author

Email: svokes@austin.utexas.edu

Phone: +1 512-232-8359

Keywords: Larynx development; foregut; epithelial to mesenchymal transition; Sonic hedgehog; vocal fold morphogenesis 


\section{Abstract}

3 The larynx enables speech while regulating swallowing and respiration. Larynx function hinges

4 on the laryngeal epithelium which originates as part of the anterior foregut and undergoes

5 extensive remodeling to separate from the esophagus and form vocal folds that interface with the

6 adjacent trachea. Here we find that Sonic hedgehog $(\mathrm{SHH})$ is essential for epithelial integrity in

7 the larynx as well as the anterior foregut. During larynx-esophageal separation, low Shh

8 expression marks specific domains of actively remodeling epithelium that undergo an epithelial to

9 mesenchymal transition (EMT) characterized by the induction of $\mathrm{N}$-Cadherin and movement of

10 cells out of the epithelial layer. Consistent with a role for $\mathrm{SHH}$ signaling in regulating this process,

11 Shh mutants undergo an abnormal EMT throughout the anterior foregut and larynx, marked by a

12 cadherin switch, movement out of the epithelial layer and cell death. Unexpectedly, Shh mutant

13 epithelial cells are replaced by a new population of Pax-1 expressing cells that form a rudimentary

14 epithelium. These findings have important implications for interpreting the etiology of $\mathrm{HH}-$

15 dependent birth defects within the foregut. We propose that $\mathrm{SHH}$ signaling has a default role in

16 maintaining epithelial identity throughout the anterior foregut and that regionalized reductions in

17 SHH trigger epithelial remodeling.

\section{Introduction}

21 The larynx produces all of the sounds for vocal communication and regulates swallowing and

22 access to the esophagus and trachea that lie directly beneath it. Congenital laryngeal

23 malformations such as tracheo-laryngeal clefts and bifid epiglottis arise from defects in early

24 laryngeal morphogenesis and impair trachea-esophageal function (feeding and breathing), as

25 well as vocalization in infants, often requiring surgical intervention and significantly impacting

26 patients' quality of life (Biesecker, 1993; Cohen et al., 2006; Johnston et al., 2014; Leboulanger 
27 and Garabédian, 2011). Complicating the etiology of these disorders, the pathways that drive the

28 early stages of larynx morphogenesis, specifically vocal fold closure and larynx-esophageal

29 separation, remain largely unknown. Several recent findings suggest that $\mathrm{HH}$ signaling may be

30 important for early larynx development. Early loss of $\mathrm{HH}$ signaling results in the reduction of

31 SOX2-expressing cells from the larynx epithelium and a failure in vocal fold closure (Lungova et

32 al., 2015). HH signaling also drives the separation of the trachea and esophagus, which are

33 directly caudal to the larynx (Billmyre et al., 2015; Han et al., 2020; loannides et al., 2010; Kim et

34 al., 2019; Kuwahara et al., 2020; Nasr et al., 2019; Que et al., 2007). Mutations in the HH pathway

35 transcriptional effector GLI3 cause dramatically altered larynx morphology and vocalization

36 defects (Tabler et al., 2017). Similarly in humans, laryngeal clefts and bifid epiglottis are

37 phenotypes of Pallister Hall syndrome which arises from truncating mutations in GLI3 (Biesecker,

38 1993; Bose, 2002; Ondrey et al., 2000). Together these defects suggest that HH signaling may

39 be required for several stages of larynx morphogenesis beyond vocal fold closure.

41 The larynx is derived from the early foregut epithelium which is regionally differentiated into

42 multiple organs, including the pharynx, parathyroid, thymus, trachea, esophagus and larynx in the

43 anterior half. Induction of these organs from the nascent gut tube, as well as subsequent

44 morphogenesis are driven by specialized types of epithelial remodeling such as budding,

45 branching, septation, and epithelial to mesenchymal transitions (EMT) (Bort et al., 2006, 2004;

46 Hebrok, 2000; Hogan and Kolodziej, 2002; Qi and Beasley, 2000), and are regulated by localized

47 signaling interactions, including $\mathrm{HH}$, between the foregut and the surrounding mesenchyme (Han

48 et al., 2020, 2017; Jacobs et al., 2012; Kraus and Grapin-Botton, 2012; Nerurkar et al., 2017;

49 Rankin et al., 2016; Zorn and Wells, 2009). In the anterior foregut, organogenesis is uniquely

50 affected by the influx of migratory neural crest-derived cell populations that combine with

51 populations of mesodermally-derived mesenchymal cells to form region-specific pharyngeal 
52 structures (Bain et al., 2016; Bhatt et al., 2013; Brito et al., 2006; Kuo and Erickson, 2010; Tabler

53 et al., 2017; Trainor and Tam, 1995).

55 Arising initially from the $4^{\text {th }}$ pharyngeal pouch and the pharyngeal floor (Figure $1 \mathrm{~A}$ ), the larynx

56 bridges the anterior-most portions of the foregut to the more posterior trachea and esophagus

57 (Henick, 1993; Lungova et al., 2015). The early stages of larynx development are characterized

58 by three major epithelial remodeling events, beginning with the stratification and zippering of the

59 lateral walls of the foregut along the midline to close the vocal folds and form the epithelial lamina.

60 Within the next 24 hours, the epithelial lamina, which joins the dorsal esophagus and the ventral

61 trachea, puckers to form the infraglottic duct, and separates from the esophagus (Henick, 1993;

62 Lungova et al., 2015). The newly separated lamina then fully recanalizes to form a laryngeal

63 lumen that is continuous with the trachea, around which specialized cartilage elements and

64 musculature are specified (Henick, 1993; Lungova et al., 2018, 2015). Epithelial morphogenesis

65 is genetically dependent upon Wnt, Hippo and $\mathrm{HH}$ signaling although the underlying mechanisms

66 remain poorly understood (Lungova et al., 2018, 2015; Mohad et al., 2021; Tabler et al., 2017).

68 We asked if and how $\mathrm{HH}$ signaling might regulate epithelial remodeling during larynx

69 development. We defined distinct domains of epithelium that downregulate Shh and undergo

70 EMT-based remodeling during larynx-esophageal separation and esophageal constriction. We

71 uncovered a similar process in $S h h^{-/}$embryos, in which epithelial cells lose expression of

72 canonical foregut genes and undergo an EMT marked by cadherin switching and ultimately cell

73 death. Despite massive cell death, the anterior foregut retains a rudimentary epithelium that now

74 contains an ectopic population of cells. These findings provide a cell-based mechanism for

75 understanding previously defined $\mathrm{HH}$-dependent vocal fold closure and laryngeal cleft defects

76 (Lungova et al., 2015). As similar changes are seen beyond the larynx, we propose a model in 
77 which regionalized reductions in $\mathrm{HH}$ drive dynamic epithelial remodeling throughout the anterior

78 foregut.

79 Results

81 Larynx epithelial cells lose Shh expression and undergo EMT based remodeling during

82 larynx-esophageal separation, and esophageal constriction.

84 To determine if Shh might regulate epithelial remodeling in the larynx, we examined its expression

85 at E11.75, when the vocal folds are remodeled to separate the larynx from the esophagus. There

86 was a wide variation in Shh expression within the larynx, with markedly reduced domains of

$87 S h h^{G F P}$ expression in the epithelial lamina at the future site of larynx-esophageal separation in

88 addition to the lateral edges of the esophagus that are in the process of constricting (Figure $1 \mathrm{~A}$ -

$89 \mathrm{~B}, \mathrm{G}-\mathrm{H}, \mathrm{K}, \mathrm{M})$. The regional reduction in GFP expression is corroborated by a loss of Shh gene

90 expression in both regions (Figure1-figure supplement 1A-D), as well as the absence of Shh-

91 descendant cells from these regions (Figure1-figure supplement 2A-B).

93 Because Shh was reduced in both regions of the larynx undergoing dynamic epithelial

94 remodeling, and previous studies observed Shh-descendant cells in the mesenchyme directly

95 adjacent to larynx-esophageal separation (Lungova et al., 2018), we asked whether the absence

96 of Shh in the larynx epithelium was accompanied by cadherin-switching and EMT. Consistent with

97 this possibility, membranous $\mathrm{N}$-Cadherin was expressed within the epithelial layer both in the

98 epithelial lamina adjacent to the infraglottic duct at the site of larynx-esophageal separation, as

99 well as along the lateral edges of the constricting esophagus (Figure 1C, E). N-Cadherin-

100 expressing cells were also present in more caudal sections of the separated larynx, overlapping

101 with the region of reduced GFP expression (Figure 1I). While there was no overall reduction in E-

102 Cadherin protein (Figure1-figure supplement 1E-I), there was an increase in punctate E-cadherin 
103 expression in both regions (Figure1-figure supplement 1 H', l'). The re-localization of E-Cadherin

104 and the concomitant initiation of $\mathrm{N}$-Cadherin at these regions provides evidence for a Cadherin-

105 switch both at the epithelial lamina and along the lateral edges of the esophagus. This is further

106 supported by the apical accumulation RAB-11, a marker of endosome recycling that is required

107 for the transport of E-Cadherin as well as N-Cadherin to the apical cell surface in multiple contexts

108 (Desclozeaux et al., 2008; Kawauchi et al., 2010; Nasr et al., 2019; Welz et al., 2014; Woichansky

109 et al., 2016) (Figure 1D,F,J,L,N).

111 To determine whether $\mathrm{N}$-Cadherin expressing cells undergo EMT within these domains we

112 examined Shh-descendant cells at E11.75 stage using a Shh ${ }^{\text {CreER}} ; R_{\text {Rosa }}{ }^{T D T}$ reporter line (Figure

113 10). Consistent with prior reports using a related Shh ${ }^{\text {Cre }}$ strategy (Lungova et al., 2018), there

114 were a small number of RFP-labeled cells within the mesenchyme along the anterior-posterior

115 axis of the separating larynx and esophagus (Figure 1P-Q). While there was a significant increase

116 in the domain of $\mathrm{N}$-Cadherin expression within the remodeling epithelium at later stages of larynx-

117 esophageal separation (Figure 1-figure supplement 2D-F), there was no significant increase in

118 the number of mesenchymal RFP-labeled cells (Figure 1-figure supplement 2B-C). This suggests

119 that some Shh-descendant cells undergo EMT-based extrusion during larynx remodeling but they

120 do not remain in the mesenchyme. Overall, these findings indicate that Shh expression is

121 dynamically regulated in the remodeling larynx, with low levels of Shh expression coinciding with

122 cadherin switching. The change in cadherin status is likely the underlying cause for the epithelial

123 cells to leave the epithelium by an EMT-like process. 
128 Our results so far indicated that regional loss of Shh was associated with cadherin switching

129 and EMT. To investigate this further, we generated RNA-seq datasets for control and $S h h^{-/}$

130 larynx tissues and identified differentially regulated genes and enriched pathways

131 (Supplemental Data Table 1). Consistent with this model, epithelial to mesenchymal transition

132 (EMT) was the most significantly enriched pathway among $\mathrm{HH}$-dependent genes (Figure 2A),

133 supporting a role for $\mathrm{HH}$ signaling in regulating this process. Differentially expressed genes

134 consisted of members of all three progressive EMT stages (Figure 2B) (Lamouille et al., 2014).

135 These included downregulation of the pro-epithelial adhesion genes $D s p$, and Dcn, which mark

136 the first stage (Bax et al., 2011; Huang et al., 2012; Kowalczyk and Nanes, 2012; Wang et al.,

137 2015; Yilmaz and Christofori, 2009). There was also an upregulation of the pro-migratory genes

138 Cdh2, Vimentin, and Fn1, indicative of the next phase of EMT (Wheelock et al., 2008; Yilmaz

139 and Christofori, 2009). Finally, there was a downregulation of Lama1, suggestive of a

140 breakdown in basement membrane which is one indicator of the third stage of EMT (Aumailley

141 and Smyth, 1998; Lamouille et al., 2014; Nakaya et al., 2008; Thiery and Chopin, 1999). In

142 addition, several TGF $\beta$ family members were up-regulated, suggesting a plausible mechanism

143 for inducing EMT (Barrallo-Gimeno and Nieto, 2005; Katsuno et al., 2013; Mercado-Pimentel

144 and Runyan, 2007; Nawshad et al., 2004; Schnaper et al., 2003; Thiery et al., 2009).

146 Consistent with the RNA-seq data and evocative of the observations in remodeling epithelia

147 (Figure 1), N-Cadherin (Cdh2) was highly upregulated within the mutant epithelium along with a 148 substantial loss of pro-epithelial E-Cadherin (Cdh1) (Figure 2C-F). This suggested that the 149 adhesive properties of the larynx epithelium were taking on a mesenchymal profile. This change 150 was further accompanied by a loss of Laminin (Lama1) from the basement membrane along the 151 epithelium (Figure $2 \mathrm{~B}, \mathrm{G}-\mathrm{H}$ ) indicating that $\mathrm{HH}$ signaling is required to maintain the integrity of this 152 structure. Additional basement membrane component genes such as Col4a2 and Nid2 were 153 upregulated by RNA-seq, suggesting that loss of Laminin may result in a compensatory increase 
154 in other basement membrane components in order to maintain membrane integrity (Jones et al.,

155 2016; Salmivirta et al., 2002) (Figure 2B). This was further supported by the persistence of a 156 morphologically intact epithelial layer in $S h h^{-/}$embryos at later stages of larynx development

157 (Figure 2-figure supplement 1A-B).

159 In some systems, the expression of Vimentin is necessary and sufficient to induce EMT (Huang 160 et al., 2012; Liu et al., 2015; Mendez et al., 2010; Vuoriluoto et al., 2011). As suggested by the

161 transcriptional increase in pro-migratory factors, there was an increase in the level of Vimentin 162 expression both within the epithelium as well as in several cells within the surrounding 163 mesenchyme in $\mathrm{Shh}^{-/}$s (Figure 2I-J). High levels of Vimentin expression also marked cells that 164 appear to be extruding from the epithelial layer into the lumen (Figure 2J", J'”), as well as clusters 165 of extruded cells within the lumen of the epithelium (Figure 2K', K"). These clusters were first seen at E10.5 and increased dramatically by E11.5 (Figure 2K-M). Overall, these observations are consistent with laryngeal epithelial cells undergoing EMT in the absence of $\mathrm{HH}$ signaling.

172 To determine the onset of this phenotype, we examined earlier stages of foregut development

173 and found a reduction in the levels of E-Cadherin in the Shh ${ }^{-/}$epithelium of the presumptive larynx

174 as early as E9.5 (Figure 3A-B). While N-Cadherin was not expressed at high levels, expression

175 of membranous $\mathrm{N}$-Cadherin was first observed in a small number of cells within the epithelial 176 layer at E9.5 and at E9.75 (Figure 3C-D, H-I, N), suggesting that $\mathrm{N}$-Cadherin was beginning to be 177 expressed at the same time that mutant epithelial cells began to downregulate E-Cadherin. This 178 is consistent with recent studies that have described co-expression of E-Cadherin and N-Cadherin 179 in cells undergoing EMT (Ray et al 2016, Aiello et al 2018). Over the next few hours of 
development E-Cadherin re-localized within cells, accumulating in puncta along the apical surface

181 (Figure 3E-G), and was almost completely gone by E10.0 (Figure 3J-K) (Aiello et al., 2018;

182 Woichansky et al., 2016). At this stage, more than half of the cells within the epithelium expressed

183 robust levels of membranous $\mathrm{N}$-Cadherin (Figure $3 \mathrm{~L}-\mathrm{N}$ ).

185 The change in cadherin status suggested a transition to a mesenchymal fate in the absence of $186 \mathrm{HH}$ signaling. Alternatively, these cells might be replaced by a different population of N-Cadherin

187 expressing cells. To distinguish between these possibilities we examined Cadherin expression in 188 larynx epithelial cells using the $S h h^{C r e E R} ; R O s a^{T D T}$ reporter line to label Shh-expressing epithelial

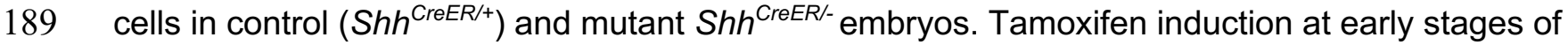
190 foregut development (E8.5) exclusively labeled epithelial cells in the vocal folds at E9.75 in control $191\left(S h h^{C r e E R /+}\right)$ and mutant $\left(S h h^{C r e E R /-}\right)$ embryos (Figure 3P-Q). While E-Cadherin and N-Cadherin 192 had mutually exclusive boundaries restricted to the epithelium and mesenchyme respectively in 193 controls, they appeared to be co-expressed within a small number of TDT-expressing epithelial 194 cells in Shh-s at E9.75 (Figure 3 P-Q; Figure 3-figure supplement 1A-B,D). Co-expression was 195 also observed at E10.0, both as distinct apical puncta as well as laterally along cell-cell boundaries 196 (Figure 3-figure supplement 1C), indicating that some laryngeal epithelial cells undergo a cadherin 197 switch in the absence of $\mathrm{HH}$ signaling. The switch in cadherin expression within the vocal folds 198 also occurred on the transcriptional level with Cdh1 expression in the mutant epithelium at E9.25 199 replaced by high levels of Cdh2 expression by E10.5 (Figure 3-figure supplement 2A-D). We 200 conclude that $\mathrm{HH}$ signaling is required for the transcriptional maintenance of $\mathrm{Cdh} 1$ along the early 201 foregut.

203 FOXA2 activates the expression of Cdh1 and suppresses EMT programs in the endoderm (Bow 204 et al., 2020; Scheibner et al., 2021; Zhang et al., 2015). This suggested that EMT initiation within $205 \mathrm{Shh}^{-/} \mathrm{s}$ might be caused by a loss of FOXA2 expression. Consistent with this notion, FOXA2 was 
expressed in nearly every cell at the region of the future larynx in both control and $S h h^{-/}$s during early stages of foregut development (E9.25; 21-23 somites; Figure 4A, Figure 4-figure supplement 1A-B). However, by E9.75 (27-29 somites), FOXA2 expression was absent from $\sim 30-40 \%$ of the mutant cells with reduced expression in many of the remaining FOXA2+ cells (Figure 4A-C, Figure 4-figure supplement 1C-F). FOXA2 was further reduced by E10.5 and completely absent by E11.5

211 (Figure 4A, Figure4-figure supplement 1G-J). This suggested that HH might prevent EMT by 212 positively regulating FOXA2 in either a cell non-autonomous or autonomous fashion. In keeping 213 with the latter possibility, there was Ptch1 and low level Gli1 expression within the larynx 214 epithelium (Figure 4-figure supplement $2 \mathrm{~A}-\mathrm{C}$ ), indicating that $\mathrm{HH}$ signaling could potentially 215 regulate FOXA2 through autocrine signaling.

Transitioning epithelial cells extrude from the epithelial layer and undergo apoptosis in the absence of $\mathrm{HH}$ signaling.

We next asked what happened to foregut epithelial cells undergoing EMT once they left the 221 epithelium. These cells could be in the process of undergoing apoptosis, as often happens with 222 extruded cells (Fadul and Rosenblatt, 2018; Kim et al., 2015; Kuipers et al., 2014; Ohsawa et al., 223 2018). Alternatively, these cells might persist in the mesenchyme adjacent to the epithelium. To 224 address this, we again used genetic fate mapping to examined the fate of larynx epithelial cells, 225 in control $\left(S h h^{C r e E R /+}\right)$ and mutant $S h h^{C r e E R /-}$ embryos (Figure 4D). While Td-Tomato labeling 226 remained restricted to the epithelial layer in control embryos (Figure 4E-G, K) there were a small 227 number of labeled cells within the mesenchyme surrounding the epithelium in mutant embryos by 228 E10.5 (Figure 4H-I, K). These cells, which were relatively rare, were consistent with EMT 229 induction, and the basal extrusion of epithelial cells in the absence of $\mathrm{HH}$ signaling (Figure $4 \mathrm{H}-\mathrm{I}$, $230 \mathrm{~K})$. Nonetheless, the low number of these cells suggested that most of the cells leaving the 231 epithelium do not survive. Consistent with this idea, there were high levels of cell death in both 
232 the mesenchymal and epithelial tissues of the vocal folds between E9.5-11.5, peaking at over

$23330 \%$ of the epithelium (Figure $4 \mathrm{H}, \mathrm{J}$; Figure4-figure supplement $3 \mathrm{~A}-\mathrm{H}$ ). Moreover, the majority of

$234 S h h^{C r e E R /-; R o s a^{T d T}}$ labeled cells outside the epithelium expressed the apoptosis marker Cleaved

235 Caspase-3 (Figure $4 \mathrm{H}, \mathrm{J})$. We conclude that most of the vocal fold cells undergoing EMT in Shh

236 - embryos are either in the process of undergoing apoptosis or undergo apoptosis shortly after

237 extrusion.

Initial Shh-expressing epithelial cells are replaced by an aberrant cell population in the

242 During the initial period of cell death, proliferation levels remained unchanged. However, by E11.5

243 there was a significant increase in cell proliferation within the vocal fold epithelium of $S h h^{-/}$

244 embryos (Figure 4-figure supplement 3I-J). This, and the persistence of a morphologically distinct

245 epithelium, implied that $\mathrm{HH}$-independent mechanisms might contribute to epithelial maintenance.

246 Notably, the $\mathrm{Shh}^{--}$epithelium was highly disorganized. Compared to the uniform, 1-2 cell layers

247 observed in control embryos, mutant embryos had highly variable epithelia containing increased

248 numbers of cell layers (an average of 12 layers; Figure 4-figure supplement 4A-C), with an overall

249 thickening of the vocal fold epithelium. This aberrant epithelium continued to persist until at least

250 E13.5, and was composed of rudimentary, poorly keratinized, p63-negative cells that do not

251 recover normal epithelial form or function (Figure 2-figure supplement 1A-B).

253 We asked if the epithelial cells that persist to later stages are descendants of the initial cells

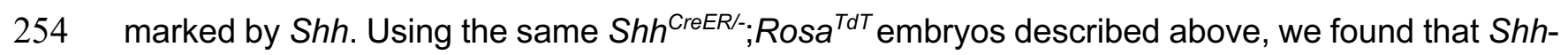

255 descendants were primarily localized to the ventral half of the vocal fold epithelium by E10.5

256 (Figure 4D-F, L). As Shh is initially expressed throughout the foregut and continues to be

257 expressed within the dorsal larynx epithelium at E11.5, this suggests that foregut epithelial cells 
undergo dynamic regional cellular rearrangements during this timepoint (Burke and Oliver, 2002; Lungova et al., 2018, 2015; Moore-Scott and Manley, 2005; Motoyama et al., 1998; Rankin et al., 2016; Sagai et al., 2009; Szabo et al., 2009). In marked contrast to control embryos, there was a $60 \%$ reduction in Shh-descendant cells in Shh ${ }^{\mathrm{CreER} /-}$ mutants (Figure $4 \mathrm{H}-\mathrm{J}, \mathrm{L}$ ), indicating that the aberrant epithelium observed at later stages was not descended from the initial epithelium. However, as Shh-descendant cells only labeled the ventral half in these experiments, this result did not rule out the possibility that a domain of dorsally located cells repopulated the ventral epithelium. To address this more directly, we examined the expression of SOX2 and NKX2.1, which respectively specify dorsal and ventral foregut domains (Kim et al., 2019; Kuwahara et al., 2020; Nasr et al., 2019; Que et al., 2007). At E10.5 there is an absence of NKX2.1 and a significant reduction in SOX2, which is undetectable by E11.5 (Figure 5A-E, Figure 5- figure supplement 1AD). We conclude that $\mathrm{HH}$ is required for the survival and regional identity of ventral and dorsal endodermal cells that together comprise the epithelium.

272 To determine the identity of the remaining cells that make up the epithelium in the absence of $\mathrm{HH}$ 273 signaling, we intersected significantly up-regulated genes found in the E10.5 Shh ${ }^{-/}$larynx RNA274 seq dataset (Figure 2A) with a published scRNA-seq dataset of lineage-specific genes generated 275 in the E9.5 endoderm (Figure 5F; Supplemental Data Table 2) (Han et al., 2020). While some 276 lineage specific markers throughout the anterior-posterior axis of the gut were increased in the $277 S_{S h}^{-/}$dataset (Figure $5 \mathrm{G}$ ), over a third of the upregulated genes within this intersection (28/74) 278 were annotated as pharyngeal genes. Pharynx-specific genes were significantly more likely to be 279 upregulated in $S h h^{-/}$larynx tissue than trachea/esophagus-specific genes $(p=3.215 e-05$, one280 tailed Fisher's exact test), a finding that was confirmed by gene-set enrichment analysis (Figure 281 5-figure supplement 2A-B). Pax1 was the most upregulated pharynx-specific gene within the Shh $282{ }^{\prime}$ dataset (Figure $5 \mathrm{H}$ ). In controls at this stage, Pax1 was expressed exclusively in the pharyngeal 283 pouches, which did not express FOXA2 or Shh (Figure 5I-J, Figure 5-figure supplement 2C,E,M) 
284 (Johansson et al., 2015; Moore-Scott and Manley, 2005; Westerlund, 2013). By E10.5, following 285 larynx specification, Pax1 continued to be expressed in the Shh-negative pharyngeal pouches, 286 and was completely absent from the epithelium and mesenchyme of the vocal folds (Figure 5K287 L) (Moore-Scott and Manley, 2005). In contrast, Shh ${ }^{-/}$embryos had ectopic Pax1 expression 288 throughout the anterior foregut endoderm and larynx. Ectopic Pax1 expression was also detected 289 in the adjacent mesenchyme of the larynx but was excluded from more posterior foregut tissues 290 such as the trachea and esophagus (Figure 5M-N; Figure 5-figure supplement 2C-L). 291 Correspondingly, FOXA2 expression was either severely reduced or absent from these regions 292 by E11.5 (Figure 5-figure supplement 2M-N). It is presently unclear whether this Pax1-expressing 293 population represents an expansion of Pax1-expressing cells from the pharyngeal pouches, an 294 expansion of a rare population of cells that is not detectable in controls, or an abnormal population 295 that is not normally found in embryos. We conclude that the initial foregut epithelium is replaced by a different population of Pax1-expressing cells. Notably, this indicates a requirement for Shh

297 in maintaining epithelial identity that extends beyond the larynx to other parts of the anterior 298 foregut.

\section{Discussion}

We have uncovered a broad role for $\mathrm{HH}$ signaling in regulating the morphogenesis of the laryngeal

303 epithelium and propose that this extends to the morphogenesis of additional anterior-foregut304 derived organs, including trachea-esophageal separation. There is an unexpectedly early role for $305 \mathrm{HH}$ signaling in maintaining the nascent foregut epithelium, which in its absence undergoes EMT 306 marked by cadherin switching, cell extrusion and ultimately cell death. As this initial population of 307 epithelium dies, it is replaced by an ectopic population of cells (Figure 6A). The unexpected 308 presence of this population complicates the previous interpretation of $\mathrm{HH}$ mutant phenotypes in 309 the anterior foregut, as changes in gene expression that have been interpreted as reflecting $\mathrm{HH}-$ 
310 dependent transcriptional changes might instead reflect the properties of the new population of

311 replacement cells.

313 The anterior foregut epithelium consists of a new population of cells with aberrant gene

\section{4 expression}

316 The loss of FOXA2, SOX2 and NKX2.1 (Figures 4,5, Figure 5-figure supplement 1,2) could be

317 due to either the transcriptional downregulation of $\mathrm{HH}$ target genes or it could reflect the absence

318 of cells that express these foregut markers. The nearly complete loss of Shh-descendant labeling

319 coupled with high levels of cell death (Figure 4; Figure 4-figure supplement 3) is consistent with

320 the latter scenario, suggesting that the descendants of Shh-expressing endodermal cells are

321 replaced by a $\mathrm{PAX} 1^{+} ; \mathrm{FOXA2} 2^{-}$population. As Pax1 normally exclusively marks the pharyngeal

322 pouches, and both Shh and FOXA2 are excluded from these regions, these cells are most likely

323 to represent the expansion or ectopic expression of this lineage (Figure 6A; Figure 5-figure

324 supplement 2C,E,M) (Johansson et al., 2015; Moore-Scott and Manley, 2005; Müller et al., 1996;

325 Okada et al., 2016; Wallin et al., 1996; Westerlund, 2013). Elevated levels of Pax1 have previously

326 been identified in the pharyngeal pouches of $S h h^{-/}$embryos and our findings indicate that this

327 extends through the larynx (Moore-Scott and Manley, 2005; Wallin et al., 1996). Consistent with

328 this tissue representing a pharyngeal pouch population, the loss of Shh has been reported to

329 result in ectopic pharyngeal pouch-derived thyroid structures at later developmental stages

330 (Fagman et al., 2004; Westerlund, 2013). We do not however detect the thyroid marker NKX2.1

331 within the $S h h^{-/}$larynx and it is presently unclear whether this might be due to a delayed onset of

332 the thyroid fate, if the expanded Pax1-positive regions contain other pharyngeal pouch-derived

333 cells or if this represents a different population of cells altogether.

335 Mechanisms underlying HH-mediated epithelial changes 
337 Prior to being lost from the foregut, FOXA2 expression is reduced in Shh ${ }^{-/}$foreguts as well as the 338 pharyngeal endoderm (Figure 4C, Figure 4-figure supplement 2D,F,H) (Yamagishi et al., 2003).

339 FoxA2 is a direct transcriptional target of $\mathrm{SHH}$ in the neural tube (Oosterveen et al., 2012; 340 Peterson et al., 2012; Sasaki and Hogan, 1994) and the HH-target genes Ptch1 and Gli1 are 341 expressed within the foregut epithelium (Figure 4-figure supplement 2A,C). This is consistent with 342 a possibility that $\mathrm{HH}$ signaling could have a role in the transcriptional maintenance of FoxA2 or 343 perhaps other epithelial genes through autocrine signaling (Motoyama et al., 1998; Yamagishi et 344 al., 2003). However, as has been previously noted in other foregut tissues, the expression of $\mathrm{HH}-$ 345 responsive target genes is much lower in the epithelium than in the mesenchyme (Figure 4-figure 346 supplement 2C) (Han et al., 2017; Moore-Scott and Manley, 2005; Motoyama et al., 1998; Rankin 347 et al., 2016). Thus, $\mathrm{HH}$ signaling could alternatively occur through a more conventional paracrine 348 signaling mechanism to regulate the surrounding mesenchyme, which would in turn regulate the 349 epithelium as previously suggested (Han et al., 2020, 2017; Nasr et al., 2021; Rankin et al., 2016; 350 Yang et al., 2021). Consistent with this possibility, there is widespread cell death in the Shh ${ }^{-/}$ 351 mesenchyme that precedes that in the epithelium (Figure 4, Figure 4-figure supplement 3G,H). 352 This results in dramatic changes to the composition of the mesenchyme, including the 353 upregulation of multiple TGFß family members that have well-established roles in inducing EMT 354 as well as antagonizing $\mathrm{HH}$ signaling during thymic/parathyroid and pancreas induction (Hebrok 355 et al., 1998; Katsuno et al., 2013; Kim and Hebrok, 2001; Mercado-Pimentel and Runyan, 2007; 356 Moore-Scott and Manley, 2005; Nawshad et al., 2004; Schnaper et al., 2003; Thiery et al., 2009).

358 FOXA2 has recently been reported to prevent EMT and to regulate the expression of N-Cadherin 359 in the nascent endoderm during gastrulation (Scheibner et al., 2021). SHH-mediated regulation 360 of FOXA2 might represent an extension of this process to the anterior foregut. In contrast to 361 gastrulation, the expression of $\mathrm{N}$-Cadherin coincides with a reduction and re-localization of E- 
362 Cadherin in the Shh ${ }^{-/}$anterior foregut (Figures 2, 3). In different contexts, E-Cadherin has been 363 reported to be a direct target of FOXA2 in oral and breast cancer cells (Bow et al., 2020; Zhang 364 et al., 2015). Thus, the reduction of FOXA2 from the endoderm could act to initiate EMT and 365 cadherin switching prior to the onset of cell death. This is consistent with a model where $\mathrm{HH}$ 366 prevents precocious EMT in the larynx epithelium by maintaining FOXA2 levels by an unknown 367 mechanism. The subsequent, widespread cell death both within the epithelium and the 368 mesenchyme of $S h h^{-/}$laryngeal tissue likely accounts for the expulsion of Shh-descendant 369 epithelial cells from the foregut endoderm, a process that is comparable to cell death-induced cell 370 extrusion in other systems (Kuipers et al., 2014; Ohsawa et al., 2018; Rosenblatt et al., 2001).

371 Curiously the gradual loss of E-Cadherin protein within $S h h^{-/ s}$ was not observed during larynx372 esophageal separation, perhaps indicating differences in $\mathrm{HH}$ requirements in the early versus late 373 remodeling larynx (Figure 1; Figure 1-figure supplement 1). Alternatively, this could be due to the 374 dynamic expression of Shh at late stages of larynx remodeling and a resulting shorter temporal window for EMT onset during larynx-esophageal separation.

377 Confirming previous studies, we find that Shh is dynamically expressed during larynx 378 development (Lungova et al., 2018, 2015; Sagai et al., 2009). Those areas where Shh expression 379 is most reduced correspond to the location of unique N-Cadherin positive domains evocative of 380 the earlier global induction of $\mathrm{N}$-Cadherin in $\mathrm{Shh}^{-/-}$foregut epithelium (Figures 1,2 ). In addition to 381 its absence from regions of the larynx epithelium that express $\mathrm{N}$-Cadherin, the relative levels of 382 Shh within Shh-expressing domains of the epithelium are highly dynamic at later stages, where 383 there is an overall reduction in Shh within the dorsal half of the larynx epithelium, which is 384 contiguous with the esophagus, compared to the ventral half (Figure 1B,H). Additionally, lower 385 levels of Shh have been reported in the trachea compared to the esophageal epithelium at later 386 stages (Nasr et al., 2021). Shh expression in the larynx is regulated by three distinct enhancers 387 that occupy largely non-overlapping regions of activity along the dorsal-ventral axis of the larynx 
388 (Sagai et al., 2017, 2009; Tsukiji et al., 2014). While it remains unclear how they are regulated, 389 differential enhancer utilization is a plausible mechanism for regional regulation of Shh along the 390 foregut.

\section{A global role for Hedgehog signaling in anterior foregut organogenesis}

394 We propose that regionalized loss of Shh within the anterior foregut triggers partial EMT as a key 395 step in driving the morphogenesis of foregut-derived organs. Alternatively, there may be additional 396 regional factors that are required to activate partial EMT upon withdrawal of $\mathrm{HH}$ signaling. $\mathrm{HH}$ is 397 locally restricted along the foregut endoderm at the initiation sites of multiple foregut-derived organs including the thymus, the pancreas, the thyroid, and the liver (Apelqvist et al., 1997; Bain

399 et al., 2016; Bort et al., 2006; Fagman et al., 2004; Gordon and Manley, 2011; Hebrok, 2000;

400 Hebrok et al., 1998; Moore-Scott and Manley, 2005; Westerlund, 2013). It is unclear why HH 401 restriction is required in these different contexts and if they share a common mechanism. The 402 liver bud is generated from foregut tissue that lacks Shh expression and subsequently undergoes 403 EMT into the adjacent mesenchyme (Bort et al., 2006; Mu et al., 2020). Additionally, loss of Shh 404 and the expression of $\mathrm{N}$-Cadherin within the foregut epithelium mark the site of the presumptive 405 dorsal and ventral pancreatic buds, though N-Cadherin is dispensable for the initial stages of 406 pancreatic budding (Esni et al., 2001; Johansson et al., 2010). While the role of Shh has not been 407 directly studied in this process, Hhex mutants, which fail to undergo EMT of the liver bud also mis408 express Shh in the epithelium (Bort et al., 2006). Given the role for FOXA2 in regulating EMT in 409 gastrulating endoderm, $\mathrm{HH}$ signaling could act either directly or indirectly to maintain FOXA2 410 (Scheibner et al., 2021). This could include the maintenance of FOXA2 expression/activity or by 411 co-regulating a set of common downstream targets. 


\section{Methods and Materials}

\section{Embryonic Manipulations}

417 All experiments involving mice were approved by the Institutional Animal Care and Use

418 Committee at the University of Texas at Austin (protocol AUP-2019-00233). The Shh ${ }^{\text {tm1amc }}$ null

419 allele (referred to as $\mathrm{Shh}^{+-}$) was maintained on a Swiss Webster background (Lewis et al., 2001).

420 The $C g$-Shh ${ }^{\text {tm1(EGFP/cre)Cjt }}\left(S h h^{\text {GFP-Cre }}\right.$ ) (Harfe et al., 2004), the Ptch1 ${ }^{\text {tm1Mps }} / J\left(P t c h^{\text {LacZ }}\right.$ ) (Goodrich et

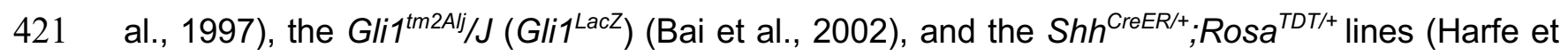
422 al., 2004; Srinivas et al., 2001) were maintained on mixed genetic backgrounds. To label Shh423 descendant cells, pregnant mice containing $S h h^{\text {CreER}} ; R_{0 s a^{T D T}}$ embryos were injected 424 intraperitoneally with 3mg of Tamoxifen (Sigma Aldrich, T5648-1G) per 40g.

\section{Gene Expression}

427 RNA was extracted using Trizol reagent (Life Technologies, 10296010) and DNAse-treated. For 428 bulk RNA-seq, vocal fold tissue was dissected from two sets of 3-pooled control and Shh ${ }^{-/}$ 429 embryos at E10.5 (32-35s). Libraries were generated using the NEBNext Ultra II Directional RNA 430 library prep kit and single-end sequenced on the Illumina NextSeq 500 platform for $\sim 40,000,000$ 431 reads/sample. Sequenced reads were aligned to the mm10 genome using HISAT2 v2.1.0 and 432 assembled into genes using StringTie v1.3.6 (Pertea et al., 2016, 2015). The data from this RNA433 seq is accessible from GEO (accession number GSE190281) and differentially expressed genes 434 are listed in Supplemental Data Table 1.

\section{Immunofluorescence}

437 All immunofluorescence replicates (denoted by $n$ ) refer to independent biological replicates from 438 different embryos. 
439 For paraffin embedding, embryos were fixed overnight in $10 \%$ formalin, sectioned to $5 \mu \mathrm{m}$ and

440 incubated in three 5 minute washes of boiling $10 \mathrm{mM}$ sodium citrate buffer, $\mathrm{pH} 6.0$ prior to antibody

441 incubation. For OCT embedding, embryos were fixed for $1 \mathrm{hr}$ in $4 \%$ paraformaldehyde at room

442 temperature, sucrose protected, embedded in OCT and sectioned to $10 \mu \mathrm{m}$. Samples were then

443 permeabilized in $0.06 \%$ PBST (Triton-X) prior to blocking. Paraffin and OCT sections were

444 blocked in $3 \%$ bovine serum albumin (BSA) and 5\% normal goat serum/PBST (0.1\% Tween-20)

445 for $1 \mathrm{hr}$ at room-temperature and, following an overnight incubation in primary antibody at $4^{\circ} \mathrm{C}$ (see

446 Supplemental Data Table 3 for a list of all antibodies), incubated in secondary antibodies for $1 \mathrm{hr}$

447 at room-temperature. Apoptosis was detected on OCT embedded sections by TUNEL staining,

448 using the In Situ Cell death detection Kit (Roche, 12156792910). All samples were counterstained

449 in 4',6-diamidino-2-phenylindole (DAPI; Invitrogen, D1306) for 10 minutes at room-temperature

450 and mounted in ProLong Gold Antifade (Thermo fisher Scientific, P36930) prior to imaging. The

451 E-Cadherin-488, N-Cadherin, TDT triple stains (Figure 2) were imaged on a Nikon Eclipse Ti-2

452 microscope equipped with a 60x, 1.40NA objective; a Visitech iSIM super-resolution confocal

453 scan head; and a Photometrics Kinetix22 camera. All other images were obtained using a Zeiss

454 LSM 710/Elyra S.1 confocal microscope and 10x, 20x, or 63x objectives.

456 To visualize E-cadherin and N-Cadherin co-expressing cells within the larynx epithelium, OCT-

457 embedded sections were permeabilized, blocked, and incubated in unconjugated N-Cadherin/

458 goat anti-rabbit Alexa 647 as specified above. Sections were then blocked in Rabbit IgG isotype

459 control (Cell Signaling Technologies, 3900S) (in 5\% normal goat serum, 1\% Triton-X, PBS) for

$4601 \mathrm{hr}$ at room-temperature. Following an overnight incubation in E-Cadherin-488 at $4^{\circ} \mathrm{C}$, samples

461 were washed in 1XPBS, counterstained with DAPI as described above, and mounted in ProLong

462 Gold Antifade. For whole-mount immunofluorescent staining, embryos were processed as

463 described by Nasr et al 2019. To image, wholemount stained embryos were embedded in $1.5 \%$

464 low-melt agarose (Sigma, A5030) cooled to room-temperature, and cleared overnight using 
465 Ce3D++ which was prepared with a high concentration of iohexol as described by Anderson et 466 al., 2020.

468 E-Cadherin localization along the apical-basal axis of the epithelium was measured in Fiji using

469 the average fluorescent intensity of E-Cadherin (normalized to background) within a selected 470 region along the lateral wall of the vocal folds, divided into 6 equal regions from the apical to the

471 basal end of the epithelium. Relative levels of RAB-11, GFP, Shh and Cdh1 along the larynx 472 epithelium was measured in Fiji using a 25- or 35pt-thick line scan that was normalized to 473 background fluorescence.

\section{Wholemount Fluorescent In situ Hybridization (HCR)}

476 All whole mount fluorescent in situ hybridization replicates (denoted by $\mathrm{n}$ ) refer to independent 477 biological replicates from different embryos.

478 Wholemount HCR was carried out on whole embryos or cultured larynx explants as previously 479 described in Choi et al., 2018, and in Anderson et al., 2020. Briefly, samples were incubated in $48016 \mathrm{nM}$ probe overnight at $37^{\circ} \mathrm{C}$, and then in $30 \mathrm{pmol}$ hairpin per $0.5 \mathrm{~mL}$ of amplification buffer 481 (Molecular Instruments) overnight at room-temperature. After incubation with the hairpins, 482 samples were washed and counterstained in DAPI overnight as specified by Anderson et al., 483 2020. Samples were then embedded in low-melt agarose and cleared in CeD3++ as described 484 (Anderson et al., 2020) before imaging. See Supplemental Data Table 3 for list of HCR probes 485 used in the study.

\section{Acknowledgements}

488 We thank John Wallingford and Dan Dickinson for comments on the paper. We thank Dan 489 Dickinson and Naomi Stolpner, for use of the Nikon Eclipse microscope. We thank Susan

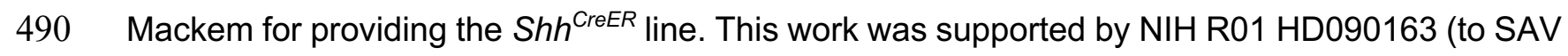


bioRxiv preprint doi: https://doi.org/10.1101/2022.01.19.476887; this version posted January 20, 2022. The copyright holder for this preprint

(which was not certified by peer review) is the author/funder, who has granted bioRxiv a license to display the preprint in perpetuity. It is made available under aCC-BY 4.0 International license.

491 and HJ), NIH R01 HD093363 (to AMZ), a Continuing Graduate Fellowship and Provost's

492 Graduate Excellence Fellowship (to JR), and a TIDES Summer Fellowship (to AEB). 


\section{References}

Aiello, N.M., Maddipati, R., Norgard, R.J., Balli, D., Li, J., Yuan, S., Yamazoe, T., Black, T., Sahmoud, A., Furth, E.E., Bar-Sagi, D., Stanger, B.Z., 2018. EMT Subtype Influences Epithelial Plasticity and Mode of Cell Migration. Dev. Cell 45, 681-695.e4. https://doi.org/10.1016/j.devcel.2018.05.027 levels critical for normal somite segmentation clock function. eLife 9, e55608. https://doi.org/10.7554/eLife.55608

Apelqvist, Å., Ahlgren, U., Edlund, H., 1997. Sonic hedgehog directs specialised mesoderm differentiation in the intestine and pancreas. Curr. Biol. 7, 801-804. https://doi.org/10.1016/S0960-9822(06)00340-X

Aumailley, M., Smyth, N., 1998. The role of laminins in basement membrane function. J. Anat. 193, 1-21. https://doi.org/10.1046/j.1469-7580.1998.19310001.x

Bai, C.B., Auerbach, W., Lee, J.S., Stephen, D., Joyner, A.L., 2002. Gli2, but not Gli1, is required for initial Shh signaling and ectopic activation of the Shh pathway. Dev. Camb. Engl. 129, 4753-4761.

Bain, V.E., Gordon, J., O’Neil, J.D., Ramos, I., Richie, E.R., Manley, N.R., 2016. Tissuespecific roles for Sonic hedgehog signaling in establishing thymus and parathyroid organ fate. Development dev.141903. https://doi.org/10.1242/dev.141903

Barrallo-Gimeno, A., Nieto, M.A., 2005. The Snail genes as inducers of cell movement and survival: implications in development and cancer. Development 132, 3151-3161. https://doi.org/10.1242/dev.01907

Bax, N.A.M., Pijnappels, D.A., van Oorschot, A.A.M., Winter, E.M., de Vries, A.A.F., van Tuyn, J., Braun, J., Maas, S., Schalij, M.J., Atsma, D.E., Goumans, M.-J., Gittenbergerde Groot, A.C., 2011. Epithelial-to-mesenchymal transformation alters electrical conductivity of human epicardial cells. J. Cell. Mol. Med. 15, 2675-2683. https://doi.org/10.1111/j.1582-4934.2011.01266.x

Bhatt, S., Diaz, R., Trainor, P.A., 2013. Signals and Switches in Mammalian Neural Crest Cell Differentiation. Cold Spring Harb. Perspect. Biol. 5, a008326-a008326. https://doi.org/10.1101/cshperspect.a008326

Biesecker, L.G., 1993. Pallister-Hall Syndrome, in: Adam, M.P., Ardinger, H.H., Pagon, R.A., Wallace, S.E., Bean, L.J., Mirzaa, G., Amemiya, A. (Eds.), GeneReviews ${ }^{\circledR}$. University of Washington, Seattle, Seattle (WA).

Billmyre, K.K., Hutson, M., Klingensmith, J., 2015. One shall become two: Separation of the esophagus and trachea from the common foregut tube. Dev. Dyn. Off. Publ. Am. Assoc. Anat. 244, 277-288. https://doi.org/10.1002/dvdy.24219

Bort, R., Martinez-Barbera, J.P., Beddington, R.S.P., Zaret, K.S., 2004. Hex homeobox genedependent tissue positioning is required for organogenesis of the ventral pancreas. Development 131, 797-806. https://doi.org/10.1242/dev.00965

Bort, R., Signore, M., Tremblay, K., Barbera, J.P.M., Zaret, K.S., 2006. Hex homeobox gene controls the transition of the endoderm to a pseudostratified, cell emergent epithelium for liver bud development. Dev. Biol. 290, 44-56. https://doi.org/10.1016/j.ydbio.2005.11.006 
Bose, J., 2002. Pallister-Hall syndrome phenotype in mice mutant for Gli3. Hum. Mol. Genet. 11, 1129-1135. https://doi.org/10.1093/hmg/11.9.1129

Bow, Y.-D., Wang, Y.-Y., Chen, Y.-K., Su, C.-W., Hsu, C.-W., Xiao, L.-Y., Yuan, S.-S., Li, R.lymph node metastasis in oral cancer. Oral Dis. 26, 756-765. https://doi.org/10.1111/odi.13282

Brito, J.M., Teillet, M.-A., Le Douarin, N.M., 2006. An early role for Sonic hedgehog from foregut endoderm in jaw development: Ensuring neural crest cell survival. Proc. Natl. Acad. Sci. 103, 11607-11612. https://doi.org/10.1073/pnas.0604751103

Burke, Z., Oliver, G., 2002. Prox1 is an early specific marker for the developing liver and pancreas in the mammalian foregut endoderm. Mech. Dev. 118, 147-155. https://doi.org/10.1016/S0925-4773(02)00240-X

Choi, H.M.T., Schwarzkopf, M., Fornace, M.E., Acharya, A., Artavanis, G., Stegmaier, J., Cunha, A., Pierce, N.A., 2018. Third-generation in situ hybridization chain reaction: multiplexed, quantitative, sensitive, versatile, robust. Development 145, dev165753. https://doi.org/10.1242/dev.165753

Cohen, S.M., Dupont, W.D., Courey, M.S., 2006. Quality-of-Life Impact of Non-Neoplastic Voice Disorders: A Meta-Analysis. Ann. Otol. Rhinol. Laryngol. 115, 128-134. https://doi.org/10.1177/000348940611500209

Desclozeaux, M., Venturato, J., Wylie, F.G., Kay, J.G., Joseph, S.R., Le, H.T., Stow, J.L., 2008. Active Rab11 and functional recycling endosome are required for E-cadherin trafficking and lumen formation during epithelial morphogenesis. Am. J. Physiol.-Cell Physiol. 295, C545-C556. https://doi.org/10.1152/ajpcell.00097.2008

Esni, F., Johansson, B.R., Radice, G.L., Semb, H., 2001. Dorsal Pancreas Agenesis in NCadherin- Deficient Mice. Dev. Biol. 238, 202-212. https://doi.org/10.1006/dbio.2001.0405

Fadul, J., Rosenblatt, J., 2018. The forces and fates of extruding cells. Curr. Opin. Cell Biol. 54, 66-71. https://doi.org/10.1016/j.ceb.2018.04.007

Fagman, H., Grände, M., Gritli-Linde, A., Nilsson, M., 2004. Genetic Deletion of Sonic Hedgehog Causes Hemiagenesis and Ectopic Development of the Thyroid in Mouse. Am. J. Pathol. 164, 1865-1872. https://doi.org/10.1016/S0002-9440(10)63745-5

Goodrich, L.V., Milenković, L., Higgins, K.M., Scott, M.P., 1997. Altered Neural Cell Fates and Medulloblastoma in Mouse patched Mutants. Science 277, 1109-1113. https://doi.org/10.1126/science.277.5329.1109

Gordon, J., Manley, N.R., 2011. Mechanisms of thymus organogenesis and morphogenesis. Development 138, 3865-3878. https://doi.org/10.1242/dev.059998

Han, L., Chaturvedi, P., Kishimoto, K., Koike, H., Nasr, T., Iwasawa, K., Giesbrecht, K., Witcher, P.C., Eicher, A., Haines, L., Lee, Y., Shannon, J.M., Morimoto, M., Wells, J.M., Takebe, T., Zorn, A.M., 2020. Single cell transcriptomics identifies a signaling network coordinating endoderm and mesoderm diversification during foregut organogenesis. Nat. Commun. 11, 4158. https://doi.org/10.1038/s41467-020-17968-X

Han, L., Xu, J., Grigg, E., Slack, M., Chaturvedi, P., Jiang, R., Zorn, A.M., 2017. Osr1 functions downstream of Hedgehog pathway to regulate foregut development. Dev. Biol. 427, 72 83. https://doi.org/10.1016/j.ydbio.2017.05.005 
Harfe, B.D., Scherz, P.J., Nissim, S., Tian, H., McMahon, A.P., Tabin, C.J., 2004. Evidence for an Expansion-Based Temporal Shh Gradient in Specifying Vertebrate Digit Identities. Cell 118, 517-528. https://doi.org/10.1016/j.cell.2004.07.024

Hebrok, M., 2000. Hedgehog signaling and pancreas development 9.

Hebrok, M., Kim, S.K., Melton, D.A., 1998. Notochord repression of endodermal Sonic hedgehog permits pancreas development 10.

Henick, D.H., 1993. Three-Dimensional Analysis of Murine Laryngeal Development. Ann. Otol. Rhinol. Laryngol. 102, 3-24. https://doi.org/10.1177/00034894931020S301

Hogan, B.L.M., Kolodziej, P.A., 2002. Molecular Mechanisms Of Tubulogenesis. Nat. Rev. Genet. 3, 513-523. https://doi.org/10.1038/nrg840

Huang, R.Y.-J., Guilford, P., Thiery, J.P., 2012. Early events in cell adhesion and polarity during epithelial-mesenchymal transition. J. Cell Sci. 125, 4417-4422. https://doi.org/10.1242/jcs.099697

Ioannides, A.S., Massa, V., Ferraro, E., Cecconi, F., Spitz, L., Henderson, D.J., Copp, A.J., 2010. Foregut separation and tracheo-oesophageal malformations: The role of tracheal outgrowth, dorso-ventral patterning and programmed cell death. Dev. Biol. 337, 351362. https://doi.org/10.1016/j.ydbio.2009.11.005

Jacobs, I.J., Ku, W.-Y., Que, J., 2012. Genetic and cellular mechanisms regulating anterior foregut and esophageal development. Dev. Biol. 369, 54-64. https://doi.org/10.1016/j.ydbio.2012.06.016

Johansson, E., Andersson, L., Örnros, J., Carlsson, T., Ingeson-Carlsson, C., Liang, S., Dahlberg, J., Jansson, S., Parrillo, L., Zoppoli, P., Barila, G.O., Altschuler, D.L., Padula, D., Lickert, H., Fagman, H., Nilsson, M., 2015. Revising the embryonic origin of thyroid C cells. Development dev.126581. https://doi.org/10.1242/dev.126581

Johansson, J.K., Voss, U., Kesavan, G., Kostetskii, I., Wierup, N., Radice, G.L., Semb, H., 2010. $\mathrm{N}$-cadherin is dispensable for pancreas development but required for $\beta$-cell granule turnover. Genes. N. Y. N 2000 48, 374-381. https://doi.org/10.1002/dvg.20628

Johnston, D.R., Watters, K., Ferrari, L.R., Rahbar, R., 2014. Laryngeal cleft: evaluation and management. Int. J. Pediatr. Otorhinolaryngol. 78, 905-911. https://doi.org/10.1016/j.ijporl.2014.03.015

Jones, F.E., Bailey, M.A., Murray, L.S., Lu, Y., McNeilly, S., Schlötzer-Schrehardt, U., Lennon, R., Sado, Y., Brownstein, D.G., Mullins, J.J., Kadler, K.E., Van Agtmael, T., 2016. ER stress and basement membrane defects combine to cause glomerular and tubular renal disease resulting from Col4a1 mutations in mice. Dis. Model. Mech. 9, 165-176. https://doi.org/10.1242/dmm.021741

Katsuno, Y., Lamouille, S., Derynck, R., 2013. TGF- $\beta$ signaling and epithelial-mesenchymal transition in cancer progression. Curr. Opin. Oncol. 25, 76-84. https://doi.org/10.1097/CCO.0b013e32835b6371

Kawauchi, T., Sekine, K., Shikanai, M., Chihama, K., Tomita, K., Kubo, K., Nakajima, K., Nabeshima, Y., Hoshino, M., 2010. Rab GTPases-Dependent Endocytic Pathways Regulate Neuronal Migration and Maturation through N-Cadherin Trafficking. Neuron 67, 588-602. https://doi.org/10.1016/j.neuron.2010.07.007

Kim, E., Jiang, M., Huang, H., Zhang, Y., Tjota, N., Gao, X., Robert, J., Gilmore, N., Gan, L., Que, J., 2019. Is11 Regulation of Nkx2.1 in the Early Foregut Epithelium Is Required for Trachea-Esophageal Separation and Lung Lobation. Dev. Cell 51, 675-683.e4. https://doi.org/10.1016/j.devcel.2019.11.002 
Kim, S., Lewis, A.E., Singh, V., Ma, X., Adelstein, R., Bush, J.O., 2015. Convergence and Extrusion Are Required for Normal Fusion of the Mammalian Secondary Palate. PLOS Biol. 13, e1002122. https://doi.org/10.1371/journal.pbio.1002122

Kim, S.K., Hebrok, M., 2001. Intercellular signals regulating pancreas development and function. Genes Dev. 15, 111-127. https://doi.org/10.1101/gad.859401

Kowalczyk, A.P., Nanes, B.A., 2012. Adherens Junction Turnover: Regulating Adhesion Through Cadherin Endocytosis, Degradation, and Recycling, in: Harris, T. (Ed.), Adherens Junctions: From Molecular Mechanisms to Tissue Development and Disease, Subcellular Biochemistry. Springer Netherlands, Dordrecht, pp. 197-222. https://doi.org/10.1007/978-94-007-4186-7_9

Kraus, M.R., Grapin-Botton, A., 2012. Patterning and shaping the endoderm in vivo and in culture. Curr. Opin. Genet. Dev. 22, 347-353. https://doi.org/10.1016/j.gde.2012.05.002

Kuipers, D., Mehonic, A., Kajita, M., Peter, L., Fujita, Y., Duke, T., Charras, G., Gale, J.E., 2014. Epithelial repair is a two-stage process driven first by dying cells and then by their neighbours. J. Cell Sci. 127, 1229-1241. https://doi.org/10.1242/jcs.138289

Kuo, B.R., Erickson, C.A., 2010. Regional differences in neural crest morphogenesis. Cell Adhes. Migr. 4, 567-585. https://doi.org/10.4161/cam.4.4.12890

Kuwahara, A., Lewis, A.E., Coombes, C., Leung, F.-S., Percharde, M., Bush, J.O., 2020. Delineating the early transcriptional specification of the mammalian trachea and esophagus. eLife 9, e55526. https://doi.org/10.7554/eLife.55526

Lamouille, S., Xu, J., Derynck, R., 2014. Molecular mechanisms of epithelial-mesenchymal transition. Nat. Rev. Mol. Cell Biol. 15, 178-196. https://doi.org/10.1038/nrm3758

Leboulanger, N., Garabédian, E.-N., 2011. Laryngo-tracheo-oesophageal clefts. Orphanet J. Rare Dis. 6, 81. https://doi.org/10.1186/1750-1172-6-81

Lewis, P.M., Dunn, M.P., McMahon, J.A., Logan, M., Martin, J.F., St-Jacques, B., McMahon, A.P., 2001. Cholesterol Modification of Sonic Hedgehog Is Required for Long-Range Signaling Activity and Effective Modulation of Signaling by Ptc1. Cell 105, 599-612. https://doi.org/10.1016/S0092-8674(01)00369-5

Liu, C.-Y., Lin, H.-H., Tang, M.-J., Wang, Y.-K., 2015. Vimentin contributes to epithelialmesenchymal transition cancer cell mechanics by mediating cytoskeletal organization and focal adhesion maturation. Oncotarget 6, 15966-15983.

Lungova, V., Verheyden, J.M., Herriges, J., Sun, X., Thibeault, S.L., 2015. Ontogeny of the mouse vocal fold epithelium. Dev. Biol. 399, 263-282. https://doi.org/10.1016/j.ydbio.2014.12.037

Lungova, V., Verheyden, J.M., Sun, X., Thibeault, S.L., 2018. Beta-Catenin signaling is essential for mammalian larynx recanalization and establishment of vocal fold progenitor cells. Development dev.157677. https://doi.org/10.1242/dev.157677

Mendez, M.G., Kojima, S.-I., Goldman, R.D., 2010. Vimentin induces changes in cell shape, motility, and adhesion during the epithelial to mesenchymal transition. FASEB J. 24, 1838-1851. https://doi.org/10.1096/fj.09-151639

Mercado-Pimentel, M.E., Runyan, R.B., 2007. Multiple Transforming Growth Factor- $\beta$ Isoforms and Receptors Function during Epithelial-Mesenchymal Cell Transformation in the Embryonic Heart. Cells Tissues Organs 185, 146-156. https://doi.org/10.1159/000101315 
Mohad, V., Lungova, V., Verheyden, J., Thibeault, S.L., 2021. Inactivation of Lats1 and Lats2 highlights the role of hippo pathway effector YAP in larynx and vocal fold epithelium morphogenesis. Dev. Biol. 473, 33-49. https://doi.org/10.1016/j.ydbio.2021.01.012

Moore-Scott, B.A., Manley, N.R., 2005. Differential expression of Sonic hedgehog along the anterior-posterior axis regulates patterning of pharyngeal pouch endoderm and pharyngeal endoderm-derived organs. Dev. Biol. 278, 323-335. https://doi.org/10.1016/j.ydbio.2004.10.027

Motoyama, J., Liu, J., Mo, R., Ding, Q., Post, M., Hui, C., 1998. Essential function of Gli2 and Gli3 in the formation of lung, trachea and oesophagus. Nat. Genet. 20, 54-57. https://doi.org/10.1038/1711

Mu, T., Xu, Liqin, Zhong, Y., Liu, X., Zhao, Z., Huang, C., Lan, X., Lufei, C., Zhou, Y., Su, Y., Xu, Luang, Jiang, M., Zhou, H., Lin, X., Wu, L., Peng, S., Liu, S., Brix, S., Dean, M., Dunn, N.R., Zaret, K.S., Fu, X.-Y., Hou, Y., 2020. Embryonic liver developmental trajectory revealed by single-cell RNA sequencing in the Foxa2eGFP mouse. Commun. Biol. 3, 642. https://doi.org/10.1038/s42003-020-01364-8

Müller, T.S., Ebensperger, C., Neubüser, A., Koseki, H., Balling, R., Christ, B., Wilting, J., 1996. Expression of AvianPax1andPax9Is Intrinsically Regulated in the Pharyngeal Endoderm, but Depends on Environmental Influences in the Paraxial Mesoderm. Dev. Biol. 178, 403-417. https://doi.org/10.1006/dbio.1996.0227

Nakaya, Y., Sukowati, E.W., Wu, Y., Sheng, G., 2008. RhoA and microtubule dynamics control cell-basement membrane interaction in EMT during gastrulation. Nat. Cell Biol. 10, 765-775. https://doi.org/10.1038/ncb1739

Nasr, T., Holderbaum, A.M., Chaturvedi, P., Agarwal, K., Kinney, J.L., Daniels, K., Trisno, S.L., Ustiyan, V., Shannon, J.M., Wells, J.M., Sinner, D., Kalinichenko, V.V., Zorn, A.M., 2021. Disruption of a Hedgehog-Foxf1-Rspo2 signaling axis leads to tracheomalacia and a loss of Sox9+ tracheal chondrocytes. Dis. Model. Mech. 14, dmm046573. https://doi.org/10.1242/dmm.046573

Nasr, T., Mancini, P., Rankin, S.A., Edwards, N.A., Agricola, Z.N., Kenny, A.P., Kinney, J.L., Daniels, K., Vardanyan, J., Han, L., Trisno, S.L., Cha, S.-W., Wells, J.M., Kofron, M.J., Zorn, A.M., 2019. Endosome-Mediated Epithelial Remodeling Downstream of Hedgehog-Gli Is Required for Tracheoesophageal Separation. Dev. Cell 51, 665-674.e6. https://doi.org/10.1016/j.devcel.2019.11.003

Nawshad, A., LaGamba, D., Hay, E.D., 2004. Transforming growth factor $\beta$ (TGF $\beta$ ) signalling in palatal growth, apoptosis and epithelial mesenchymal transformation (EMT). Arch. Oral Biol. 49, 675-689. https://doi.org/10.1016/j.archoralbio.2004.05.007

Nerurkar, N.L., Mahadevan, L., Tabin, C.J., 2017. BMP signaling controls buckling forces to modulate looping morphogenesis of the gut. Proc. Natl. Acad. Sci. 114, 2277-2282. https://doi.org/10.1073/pnas.1700307114

Ohsawa, S., Vaughen, J., Igaki, T., 2018. Cell Extrusion: A Stress-Responsive Force for Good or Evil in Epithelial Homeostasis. Dev. Cell 44, 284-296. https://doi.org/10.1016/j.devcel.2018.01.009

Okada, K., Inohaya, K., Mise, T., Kudo, A., Takada, S., Wada, H., 2016. Reiterative expression of pax1 directs pharyngeal pouch segmentation in medaka. Dev. Camb. Engl. 143, 18001810. https://doi.org/10.1242/dev.130039

Ondrey, F., Griffith, A., Van Waes, C., Rudy, S., Peters, K., McCullagh, L., Biesecker, L.G., 2000. Asymptomatic laryngeal malformations are common in patients with Pallister-Hall 
syndrome. Am. J. Med. Genet. 94, 64-67. https://doi.org/10.1002/1096-

8628(20000904)94:1<64::AID-AJMG13>3.0.CO;2-D

Oosterveen, T., Kurdija, S., Alekseenko, Z., Uhde, C.W., Bergsland, M., Sandberg, M., Andersson, E., Dias, J.M., Muhr, J., Ericson, J., 2012. Mechanistic Differences in the Transcriptional Interpretation of Local and Long-Range Shh Morphogen Signaling. Dev. Cell 23, 1006-1019. https://doi.org/10.1016/j.devcel.2012.09.015

Pertea, M., Kim, D., Pertea, G., Leek, J.T., Salzberg, S.L., 2016. Transcript-level expression analysis of RNA-seq experiments with HISAT, StringTie, and Ballgown. Nat. Protoc. 11, 1650-1667. https://doi.org/10.1038/nprot.2016.095

Pertea, M., Pertea, G.M., Antonescu, C.M., Chang, T.-C., Mendell, J.T., Salzberg, S.L., 2015. StringTie enables improved reconstruction of a transcriptome from RNA-seq reads. Nat. Biotechnol. 33, 290-295. https://doi.org/10.1038/nbt.3122

Peterson, K.A., Nishi, Y., Ma, W., Vedenko, A., Shokri, L., Zhang, X., McFarlane, M., Baizabal, J.-M., Junker, J.P., van Oudenaarden, A., Mikkelsen, T., Bernstein, B.E., Bailey, T.L., Bulyk, M.L., Wong, W.H., McMahon, A.P., 2012. Neural-specific Sox2 input and differential Gli-binding affinity provide context and positional information in Shhdirected neural patterning. Genes Dev. 26, 2802-2816. https://doi.org/10.1101/gad.207142.112

Qi, B.Q., Beasley, S.W., 2000. Stages of normal tracheo-bronchial development in rat embryos: Resolution of a controversy. Dev. Growth Differ. 42, 145-153. https://doi.org/10.1046/j.1440-169x.2000.00488.x

Que, J., Okubo, T., Goldenring, J.R., Nam, K.-T., Kurotani, R., Morrisey, E.E., Taranova, O., Pevny, L.H., Hogan, B.L.M., 2007. Multiple dose-dependent roles for Sox 2 in the patterning and differentiation of anterior foregut endoderm. Dev. Camb. Engl. 134, 25212531. https://doi.org/10.1242/dev.003855

Rankin, S.A., Han, L., McCracken, K.W., Kenny, A.P., Anglin, C.T., Grigg, E.A., Crawford, C.M., Wells, J.M., Shannon, J.M., Zorn, A.M., 2016. A Retinoic Acid-Hedgehog Cascade Coordinates Mesoderm-Inducing Signals and Endoderm Competence during Lung Specification. Cell Rep. 16, 66-78. https://doi.org/10.1016/j.celrep.2016.05.060

Rosenblatt, J., Raff, M.C., Cramer, L.P., 2001. An epithelial cell destined for apoptosis signals its neighbors to extrude it by an actin- and myosin-dependent mechanism. Curr. Biol. 11, 1847-1857. https://doi.org/10.1016/S0960-9822(01)00587-5

Sagai, T., Amano, T., Maeno, A., Kimura, T., Nakamoto, M., Takehana, Y., Naruse, K., Okada, N., Kiyonari, H., Shiroishi, T., 2017. Evolution of Shh endoderm enhancers during morphological transition from ventral lungs to dorsal gas bladder. Nat. Commun. 8, 14300. https://doi.org/10.1038/ncomms 14300

Sagai, T., Amano, T., Tamura, M., Mizushina, Y., Sumiyama, K., Shiroishi, T., 2009. A cluster of three long-range enhancers directs regional Shh expression in the epithelial linings. Development 136, 1665-1674. https://doi.org/10.1242/dev.032714

Salmivirta, K., Talts, J.F., Olsson, M., Sasaki, T., Timpl, R., Ekblom, P., 2002. Binding of Mouse Nidogen-2 to Basement Membrane Components and Cells and Its Expression in Embryonic and Adult Tissues Suggest Complementary Functions of the Two Nidogens. Exp. Cell Res. 279, 188-201. https://doi.org/10.1006/excr.2002.5611

Sasaki, H., Hogan, B.L.M., 1994. HNF-3 $\beta$ as a regulator of floor plate development. Cell 76, 103-115. https://doi.org/10.1016/0092-8674(94)90176-7 
Scheibner, K., Schirge, S., Burtscher, I., Büttner, M., Sterr, M., Yang, D., Böttcher, A., Ansarullah, Irmler, M., Beckers, J., Cernilogar, F.M., Schotta, G., Theis, F.J., Lickert, H., 2021. Epithelial cell plasticity drives endoderm formation during gastrulation. Nat. Cell Biol. 23, 692-703. https://doi.org/10.1038/s41556-021-00694-X

Schnaper, H.W., Hayashida, T., Hubchak, S.C., Poncelet, A.-C., 2003. TGF- $\beta$ signal transduction and mesangial cell fibrogenesis. Am. J. Physiol.-Ren. Physiol. 284, F243F252. https://doi.org/10.1152/ajprenal.00300.2002

Srinivas, S., Watanabe, T., Lin, C.-S., Tanabe, Y., Jessell, T.M., Costantini, F., 2001. Cre reporter strains produced by targeted insertion of EYFP and ECFP into the ROSA26 locus. BMC Dev. Biol. 8.

Szabo, N.-E., Zhao, T., Cankaya, M., Theil, T., Zhou, X., Alvarez-Bolado, G., 2009. Role of Neuroepithelial Sonic hedgehog in Hypothalamic Patterning. J. Neurosci. 29, 6989-7002. https://doi.org/10.1523/JNEUROSCI.1089-09.2009

Tabler, J.M., Rigney, M.M., Berman, G.J., Gopalakrishnan, S., Heude, E., Al-lami, H.A., Yannakoudakis, B.Z., Fitch, R.D., Carter, C., Vokes, S., Liu, K.J., Tajbakhsh, S., Egnor, S.R., Wallingford, J.B., 2017. Cilia-mediated Hedgehog signaling controls form and function in the mammalian larynx. eLife 6, e19153. https://doi.org/10.7554/eLife.19153

Thiery, J.P., Acloque, H., Huang, R.Y.J., Nieto, M.A., 2009. Epithelial-Mesenchymal Transitions in Development and Disease. Cell 139, 871-890. https://doi.org/10.1016/j.cell.2009.11.007

Thiery, J.P., Chopin, D., 1999. Epithelial Cell Plasticity in Development and Tumor Progression 12.

Trainor, P.A., Tam, P.P., 1995. Cranial paraxial mesoderm and neural crest cells of the mouse embryo: co-distribution in the craniofacial mesenchyme but distinct segregation in branchial arches. Development 121, 2569-2582. https://doi.org/10.1242/dev.121.8.2569

Tsukiji, N., Amano, T., Shiroishi, T., 2014. A novel regulatory element for Shh expression in the lung and gut of mouse embryos. Mech. Dev. 131, 127-136. https://doi.org/10.1016/j.mod.2013.09.003

Vuoriluoto, K., Haugen, H., Kiviluoto, S., Mpindi, J.-P., Nevo, J., Gjerdrum, C., Tiron, C., Lorens, J.B., Ivaska, J., 2011. Vimentin regulates EMT induction by Slug and oncogenic H-Ras and migration by governing Axl expression in breast cancer. Oncogene 30, 14361448. https://doi.org/10.1038/onc.2010.509

Wallin, J., Eibel, H., Neubüser, A., Wilting, J., Koseki, H., Balling, R., 1996. Pax1 is expressed during development of the thymus epithelium and is required for normal T-cell maturation. Dev. Camb. Engl. 122, 23-30.

Wang, S., Du, S., Wu, Q., Hu, J., Li, T., 2015. Decorin Prevents Retinal Pigment Epithelial Barrier Breakdown Under Diabetic Conditions by Suppressing p38 MAPK Activation. Invest. Ophthalmol. Vis. Sci. 56, 2971-2979. https://doi.org/10.1167/iovs.14-15874

Welz, T., Wellbourne-Wood, J., Kerkhoff, E., 2014. Orchestration of cell surface proteins by Rab11. Trends Cell Biol. 24, 407-415. https://doi.org/10.1016/j.tcb.2014.02.004

Westerlund, J., 2013. Misguided Migration of C Cell Precursors to Extra-Thyroidal Locations Related to Defective Pharyngeal Pouch Development in Shh Deficient Mice. Cell Dev. Biol. 02. https://doi.org/10.4172/2168-9296.1000129

Wheelock, M.J., Shintani, Y., Maeda, M., Fukumoto, Y., Johnson, K.R., 2008. Cadherin switching. J. Cell Sci. 121, 727-735. https://doi.org/10.1242/jcs.000455 
Woichansky, I., Beretta, C.A., Berns, N., Riechmann, V., 2016. Three mechanisms control Ecadherin localization to the zonula adherens. Nat. Commun. 7, 10834. https://doi.org/10.1038/ncomms10834 Yamagishi, C., Srivastava, D., 2003. Tbxl is regulated by tissue-specific forkhead proteins through a common Sonic hedgehog-responsive enhancer. Genes Dev. 17, 269 281. https://doi.org/10.1101/gad.1048903

Yang, Y., Paivinen, P., Xie, C., Krup, A.L., Makela, T.P., Mostov, K.E., Reiter, J.F., 2021. Ciliary Hedgehog signaling patterns the digestive system to generate mechanical forces driving elongation. Nat. Commun. 12, 7186. https://doi.org/10.1038/s41467-021-27319-z

Yilmaz, M., Christofori, G., 2009. EMT, the cytoskeleton, and cancer cell invasion. Cancer Metastasis Rev. 28, 15-33. https://doi.org/10.1007/s10555-008-9169-0

Zhang, Z., Yang, C., Gao, W., Chen, T., Qian, T., Hu, J., Tan, Y., 2015. FOXA2 attenuates the epithelial to mesenchymal transition by regulating the transcription of E-cadherin and ZEB2 in human breast cancer. Cancer Lett. 361, 240-250. https://doi.org/10.1016/j.canlet.2015.03.008

Zorn, A.M., Wells, J.M., 2009. Vertebrate Endoderm Development and Organ Formation. Annu. Rev. Cell Dev. Biol. 25, 221-251. https://doi.org/10.1146/annurev.cellbio.042308.113344 
bioRxiv preprint doi: https://doi.org/10.1101/2022.01.19.476887; this version posted January 20, 2022. The copyright holder for this preprint (which was not certified by peer review) is the author/funder, who has granted bioRxiv a license to display the preprint in perpetuity. It is made available under aCC-BY 4.0 International license.

Accumulated

A

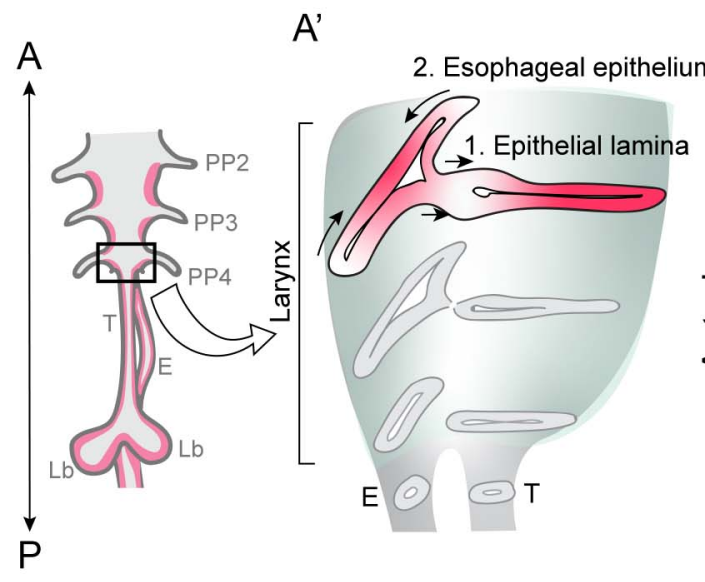

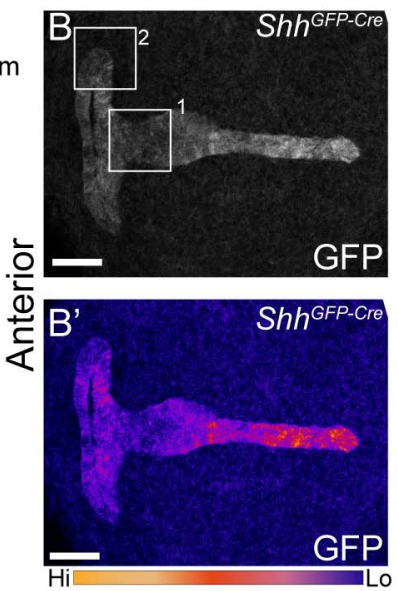
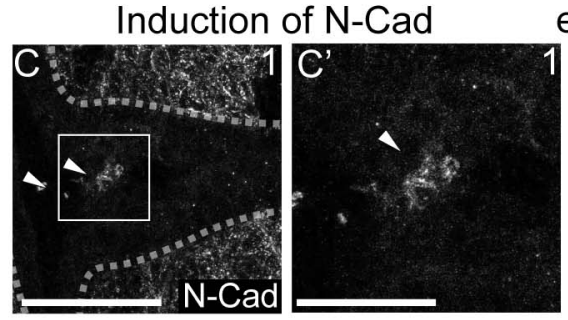
endosome recycling
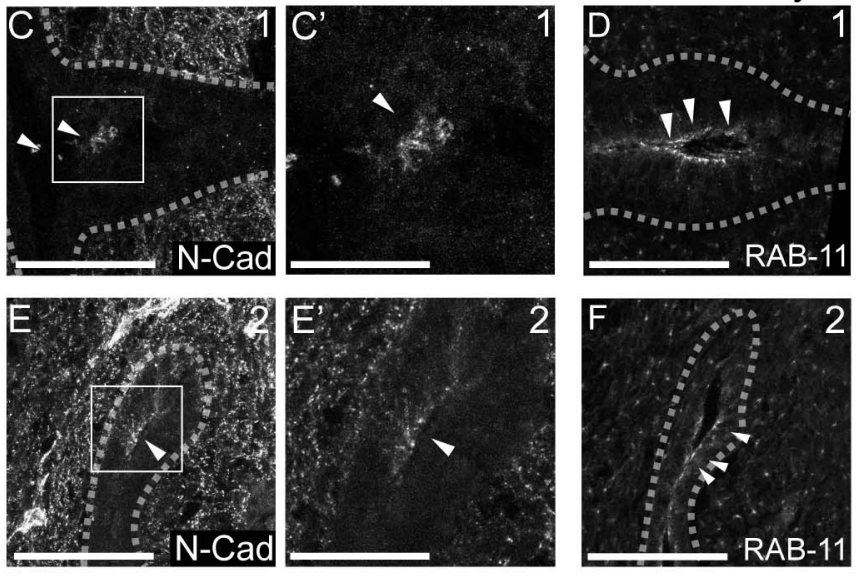

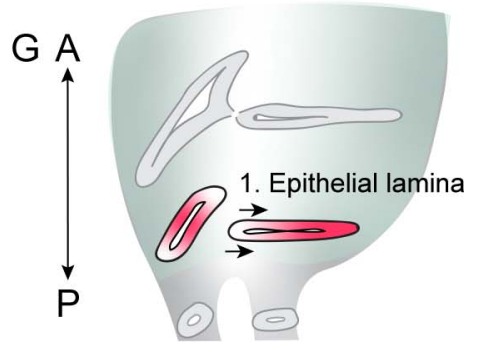

K

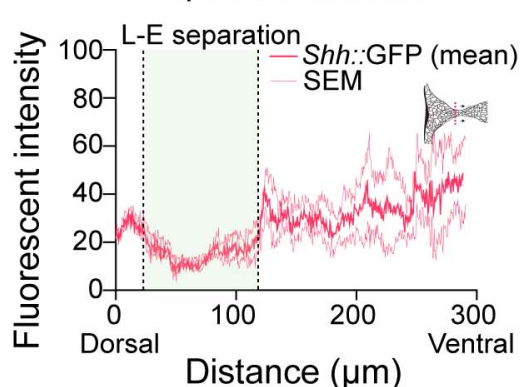

Epithelial Lamina

Distance $(\mu \mathrm{m})$

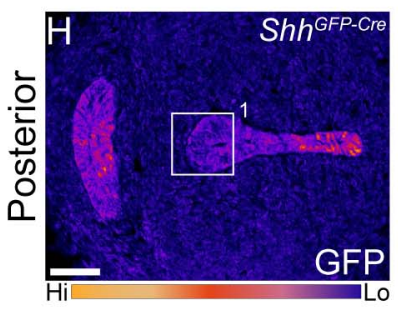

L $\quad$ Epithelial Lamina

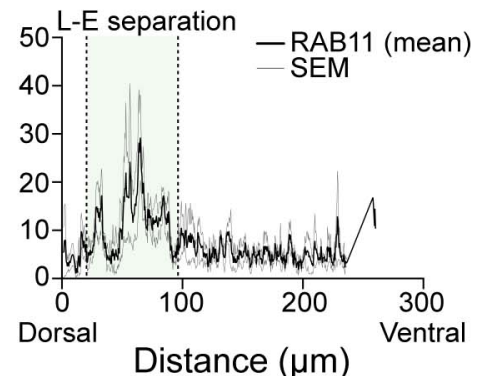

Distance $(\mu \mathrm{m})$
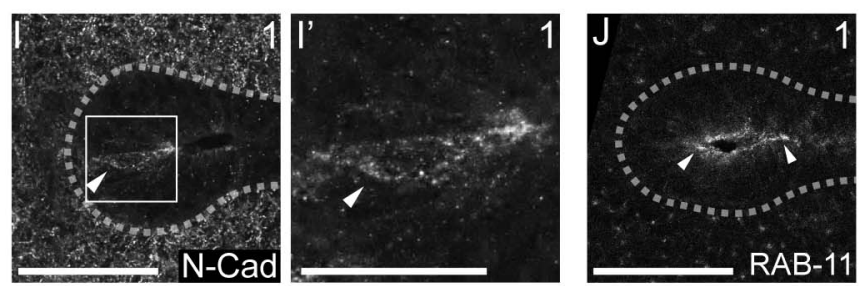

M Esophageal epithelium

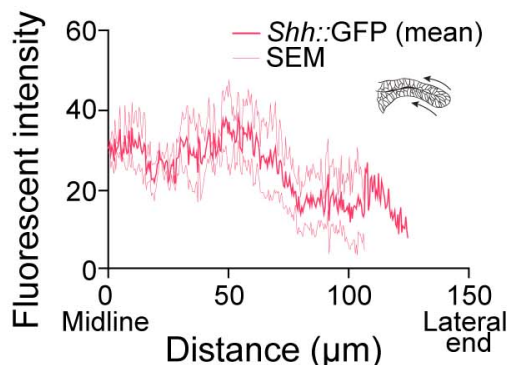

$\mathrm{N}$ Esophageal epithelium

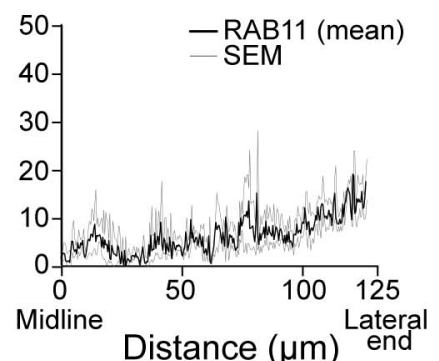

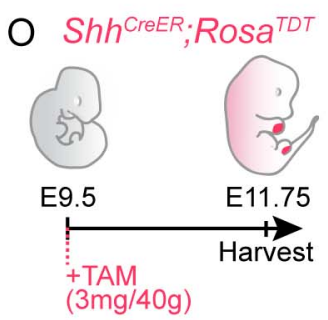
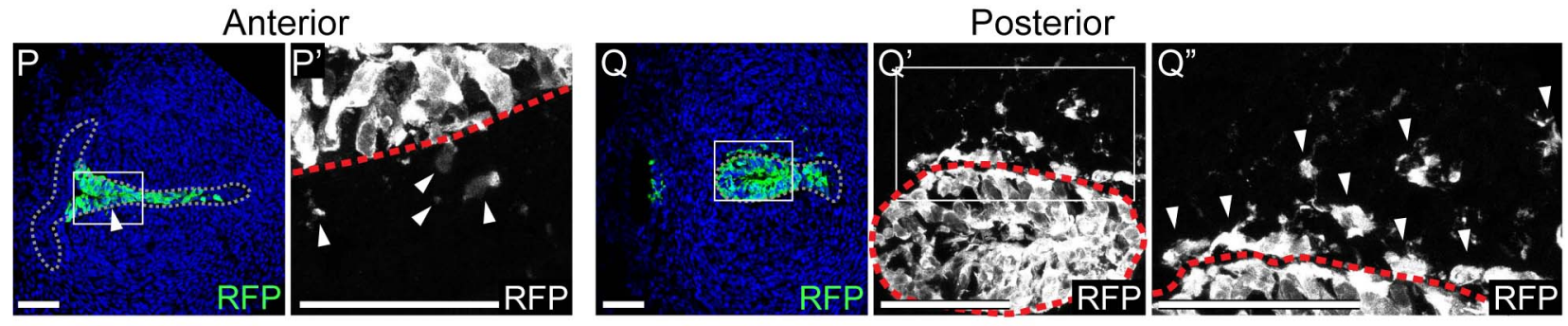

\section{Figure 1. Actively remodeling epithelial cells have low Shh expression and undergo EMT during larynx-}

esophageal separation and esophageal constriction. A, G. Schematic of the anterior foregut (A) and highlight of the anterior (A') and posterior (G) larynx at E11.75. A, B, H GFP marking Shh expression in the anterior and posterior larynx ( $n=5$ for each). There is reduced GFP expression at the epithelial lamina which fuses and then separates the larynx and esophagus (region 1; B,H), and the constricting esophageal opening (region 2; B) of the larynx. $\mathrm{C}, \mathrm{E}-\mathrm{E}, \mathrm{I}, \mathrm{I}$. Expression of N-Cadherin at anterior or posterior regions at E11.75 (n=3) . D,F,J. RAB-11 was visualized at regions $1(D, J)$ and $2(F)$ in 3 larynxes. K, M. Relative GFP expression along the epithelium at regions $1(K)$ and 2 (M) was measured and averaged across 3 replicates by line scans of fluorescent intensity. Standard error of mean was calculated across all 3 replicates and plotted in light pink. L,N. Relative RAB-11 expression was measured by lines scans of fluorescent intensity along the epithelium at regions $1(\mathrm{~L})$ and $2(\mathrm{~N})$ and averaged across 3 replicates. Standard error of mean was calculated across all 3 replicates and plotted in gray. O-Q. Shh-descendant cells were

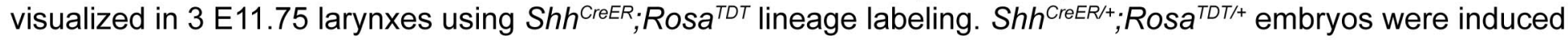
with Tamoxifen at E9.5 and analyzed for RFP (green) expression (P-Q) at E11.75 along the anterior-posterior axis of the larynx. A-anterior; P-posterior; PP 2/3/4, Pharyngeal pouches \#2-4, Lar-larynx, T-trachea, E-esophagus, Lb-lung buds. C',E',I'. Scale bars denote $25 \mu \mathrm{m}$. All other scale bars denote $50 \mu \mathrm{m}$. 
A

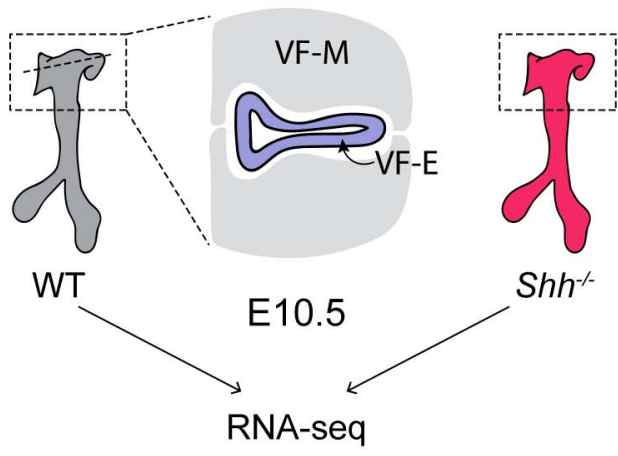

Hallmark pathway analysis for 1873

$\mathrm{HH}$-responsive genes

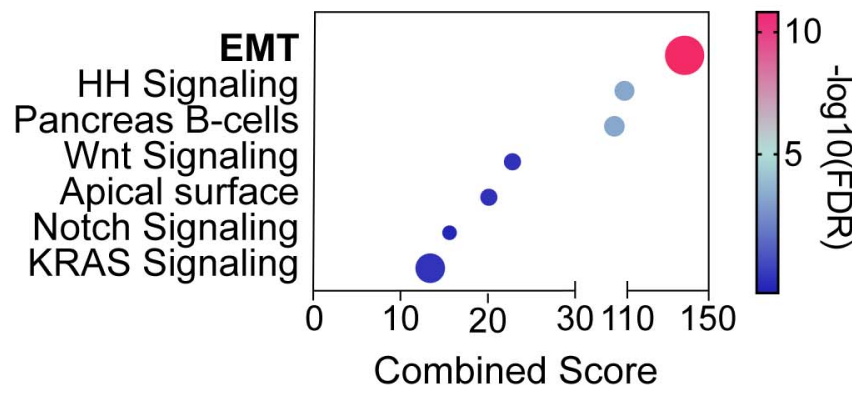

B Stage-specific EMT genes are enriched within $\mathrm{Shh}^{-} \mathrm{s}$

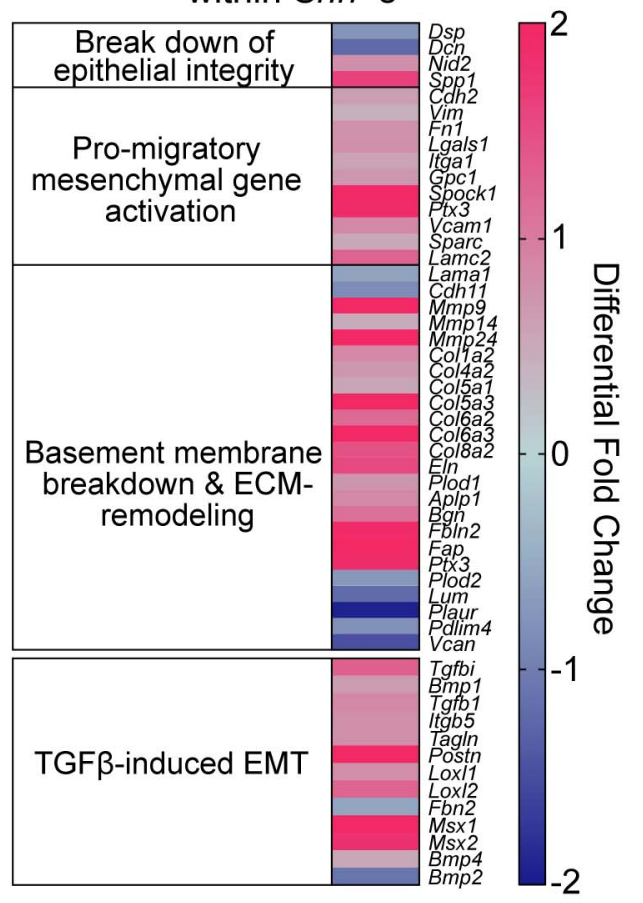

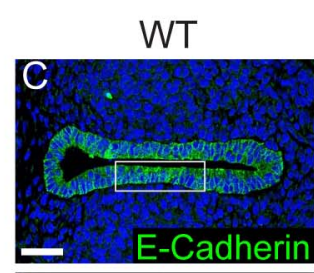
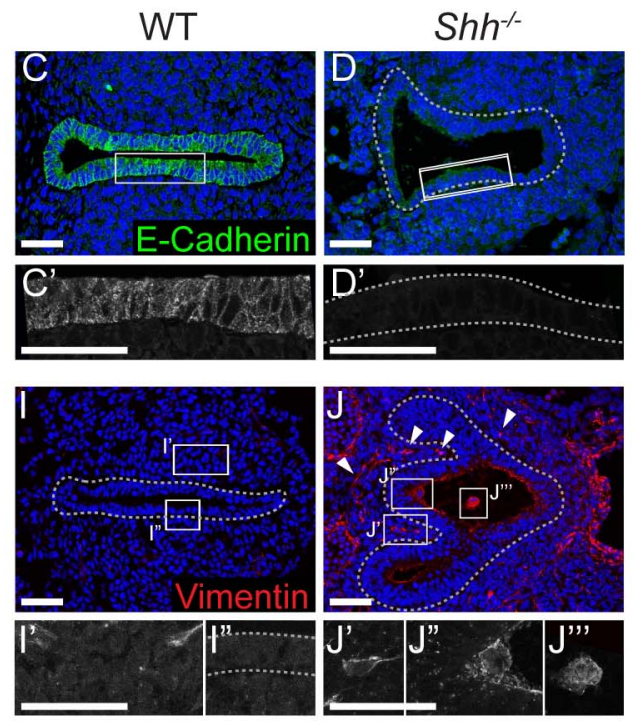
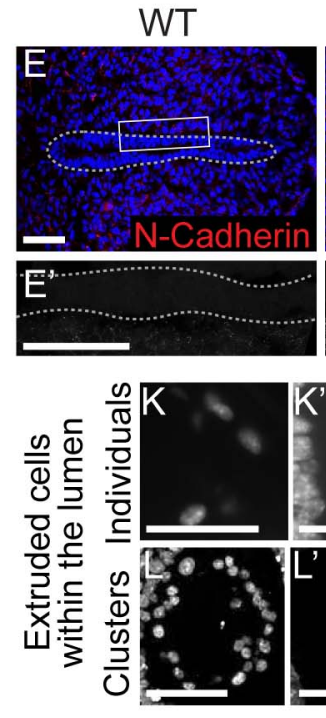
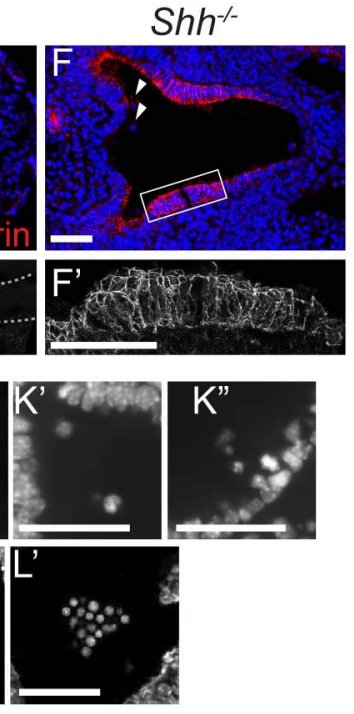
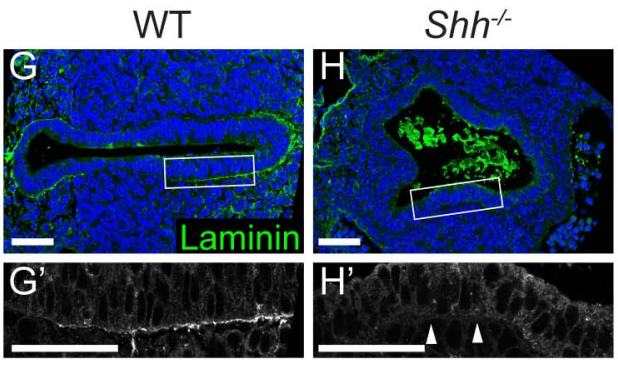

M Total extruded cells

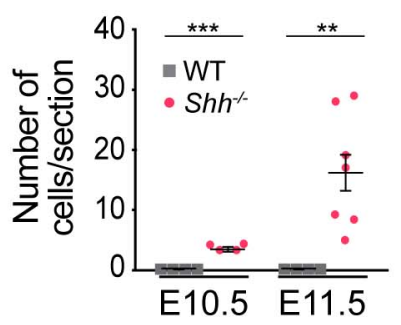

Figure 2. Larynx epithelial cells undergo ectopic EMT-like cell extrusion in the absence of $\mathrm{HH}$ signaling. A. RNA-seq of wild-type (WT) and Shh- larynx tissue at E10.5 identified $1873 \mathrm{HH}$-dependent genes $(p<0.05)$. Epithelial-to-mesenchymal transition (EMT)-related genes were highly enriched among HH targets by Hallmark pathway analysis. B. Differentially expressed EMT-genes cluster into stage-specific groups. C-D. E-Cadherin (green) expression in the epithelium across 3 controls and $3 \mathrm{Shh}^{-\mathrm{s}}$ at E10.5. E-F. N-Cadherin (red) expression within the epithelium of 3 controls and $3 \mathrm{Shh}^{-/}$s. Arrowheads mark cells in the lumen. G-H. Laminin (green) expression marking the basement membrane in 3 controls and $3 \mathrm{Shh}^{-1} \mathrm{~s}$. Arrowheads indicate loss of Laminin from the basement membrane in $S h h^{--}$s. I-J. Vimentin (red) expression to mark migrating cells in 3 control and $3 S^{-1-}$ larynxes at E10.5. Arrowheads mark Vimentin-expressing cells within the lumen (J", J'") and the surrounding mesenchyme (J') in Shh-s. K-M. DAPI staining marking cells within the lumen of the larynx in Shh ${ }^{-1}$ s at E10.5 and E11.5. M. Total number of luminal cells/section were quantified in 4 control and $4 \mathrm{Shh}^{-/ \mathrm{s}}$ at E10.5 and in 4 controls and $7 \mathrm{Shh}^{-/ \mathrm{s}}$ at E11.5. Average numbers of luminal cells/section were analyzed for statistical significance using the Student's t-test. Error bars show the standard error of the mean. ${ }^{* *} p<0.005^{* * *} p<0.0005$. VF-M-vocal fold mesenchyme; VF-E-vocal fold epithelium. All scale bars denote $50 \mu \mathrm{m}$. 
bioRxiv preprint doi: https://doi.org/10.1101/2022.01.19.476887; this version posted January 20, 2022. The copyright holder for this preprint (which was not certified by peer review) is the author/funder, who has granted bioRxiv a license to display the preprint in perpetuity. It is made available under aCC-BY 4.0 International license.

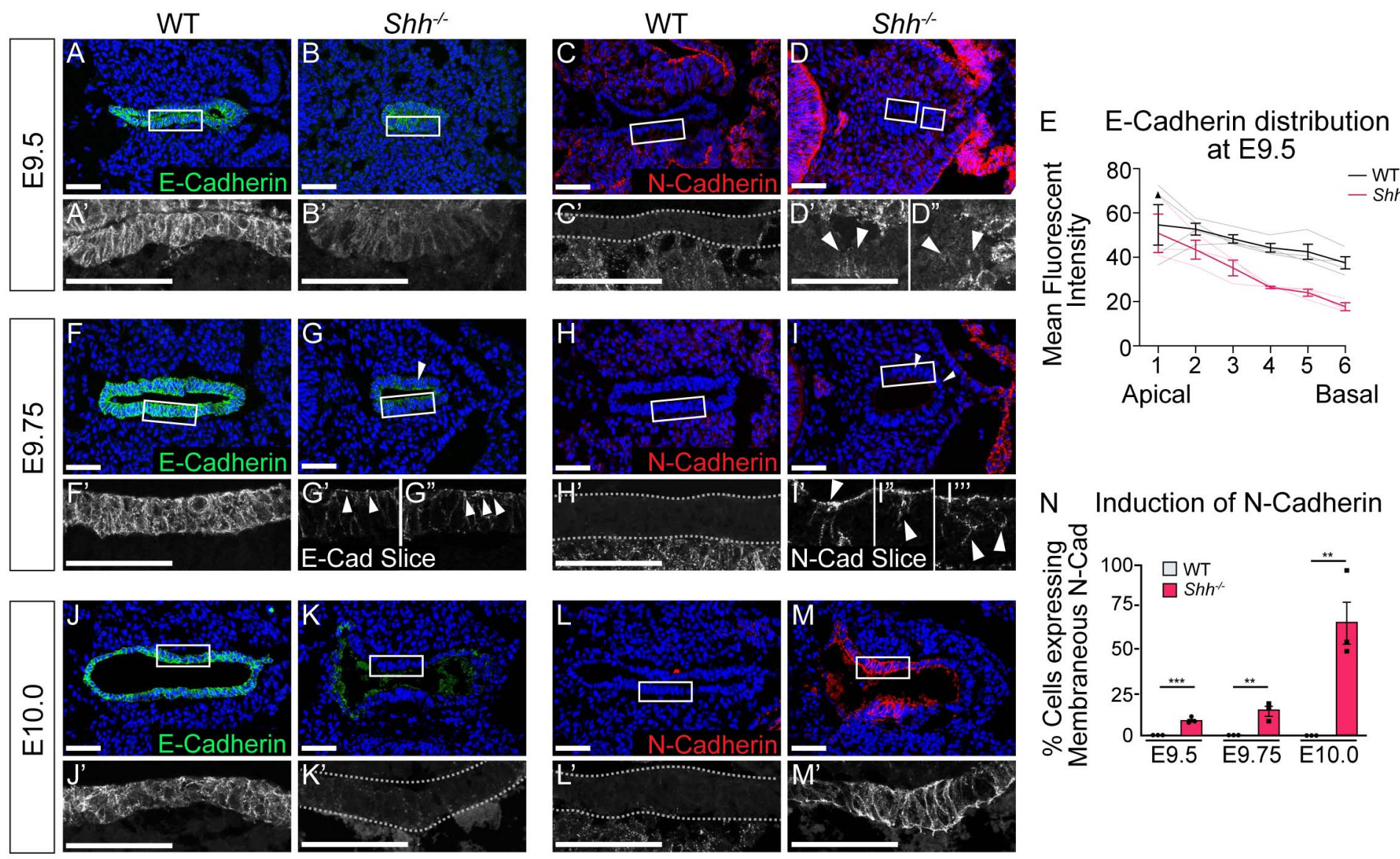

O Labeling transitioning Shh-descendant cells

$\operatorname{Shh}^{\text {CrEER; }}$ ROSa ${ }^{T D T} ; \mathrm{Shh}^{+/}$

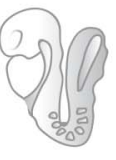

E8.5

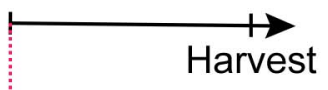

+ TAM

$(3 \mathrm{mg} / 40 \mathrm{~g})$
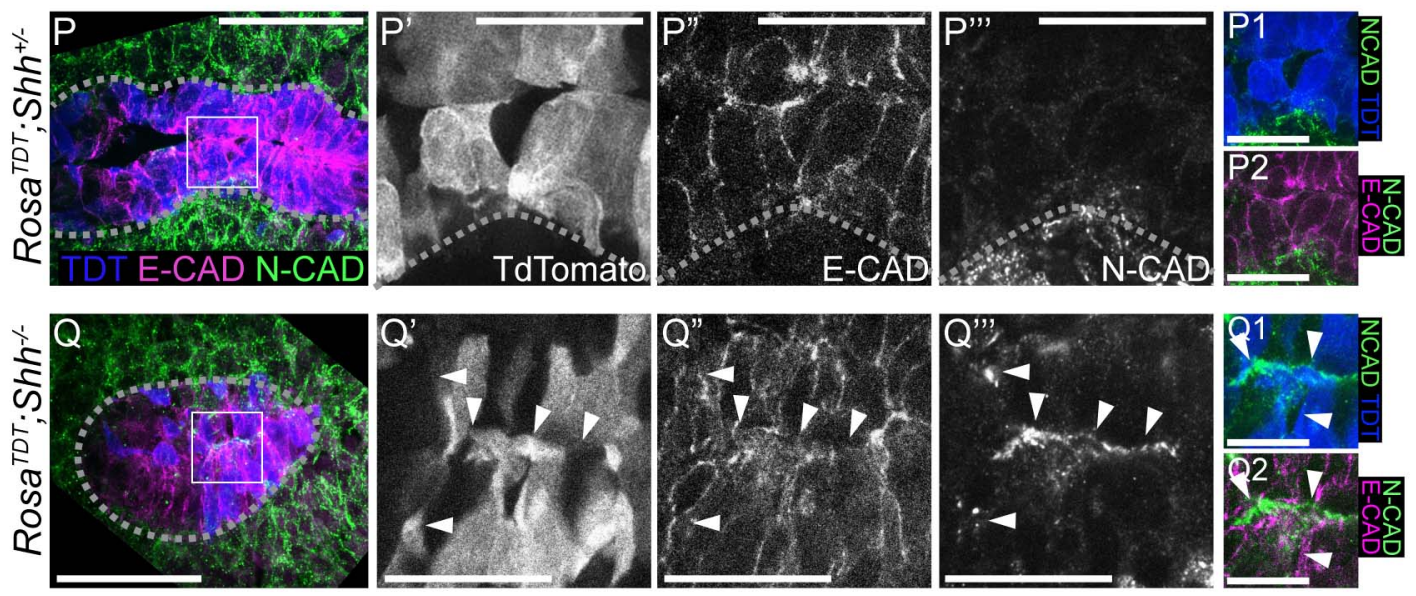

Figure 3. HH signaling is required to prevent a cadherin-switch within the epithelium during early stages of foregut development. A-D. E-cadherin expression (A-B; green) and N-cadherin expression (C-D; red) in 4 control and $3 \mathrm{Shh}^{-1}$ larynxes at E9.5 (24-26 somites). E. E-Cadherin distribution along the apical-basal axis of the epithelium in 4 controls and $3 \mathrm{Shh}^{-/ \mathrm{s}}$ at E9.5. Error bars show standard error of the mean. F-I. E-cadherin expression (F-G; green) and $\mathrm{N}$-cadherin expression ( $\mathrm{H}-\mathrm{l}$; red) in 3 control and $3 \mathrm{Shh}^{-/}$larynxes at E9.75 (27-29 somites). J-M. E-cadherin expression (J-K; green) and $\mathrm{N}$-cadherin expression (L-M; red) was examined in 3 control and 3 Shh $^{-/-}$larynxes at E10.0 (29-31 somites). N. The percentage of N-Cadherin-expressing cells within the epithelium at E9.5, E9.75 and E10.0 was averaged across 3 controls and $3 \mathrm{Sh} \mathrm{h}^{-/}$larynxes at each stage and analyzed for significance using the Student's t-test $\left({ }^{* *} p<0.00{ }^{* * *} p<0.0005\right)$. Error bars indicate the standard error of the mean. O. Shh-fate map-

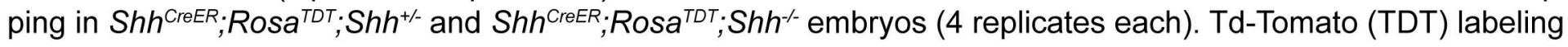
was induced with Tamoxifen at E8.5 and visualized at E9.75. P-Q. Sections were analyzed for E-Cadherin (E-CAD; magenta) and N-Cadherin (N-CAD; green) expression as well as Td-Tomato (TDT; blue) expression. Arrowheads mark regions of $\mathrm{E}$-Cadherin and $\mathrm{N}$-Cadherin expression along the membrane of a Td-Tomato-positive cell. $\mathrm{P}^{\prime}-\mathrm{P} 2, \mathrm{Q}^{\prime}-\mathrm{Q} 2$. Scale bars denote $25 \mu \mathrm{m}$. All other scale bars denote $50 \mu \mathrm{m}$. 


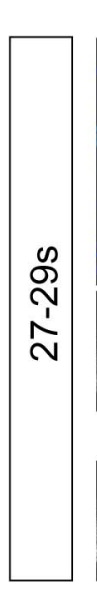

WT

A
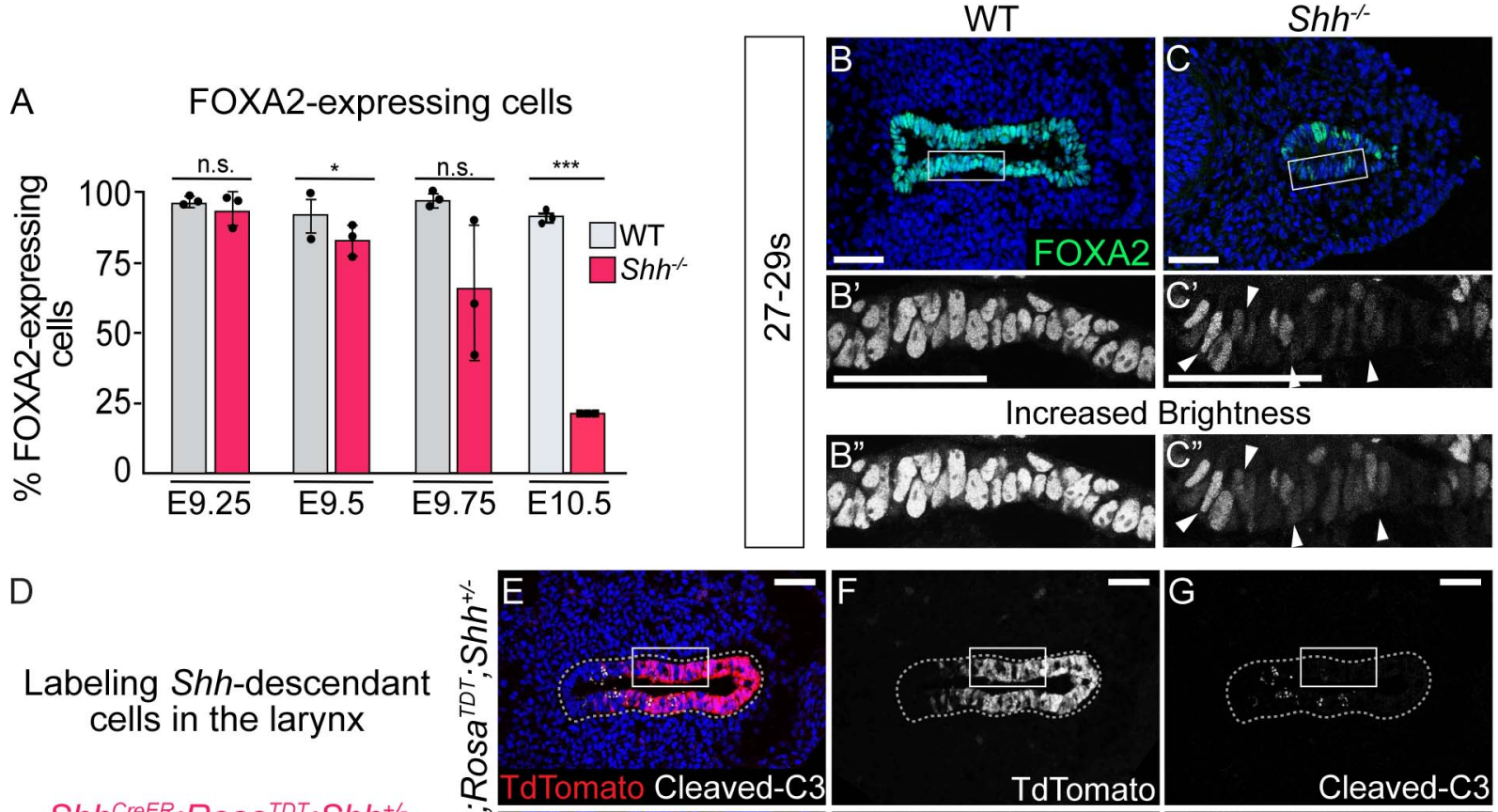

E8.5
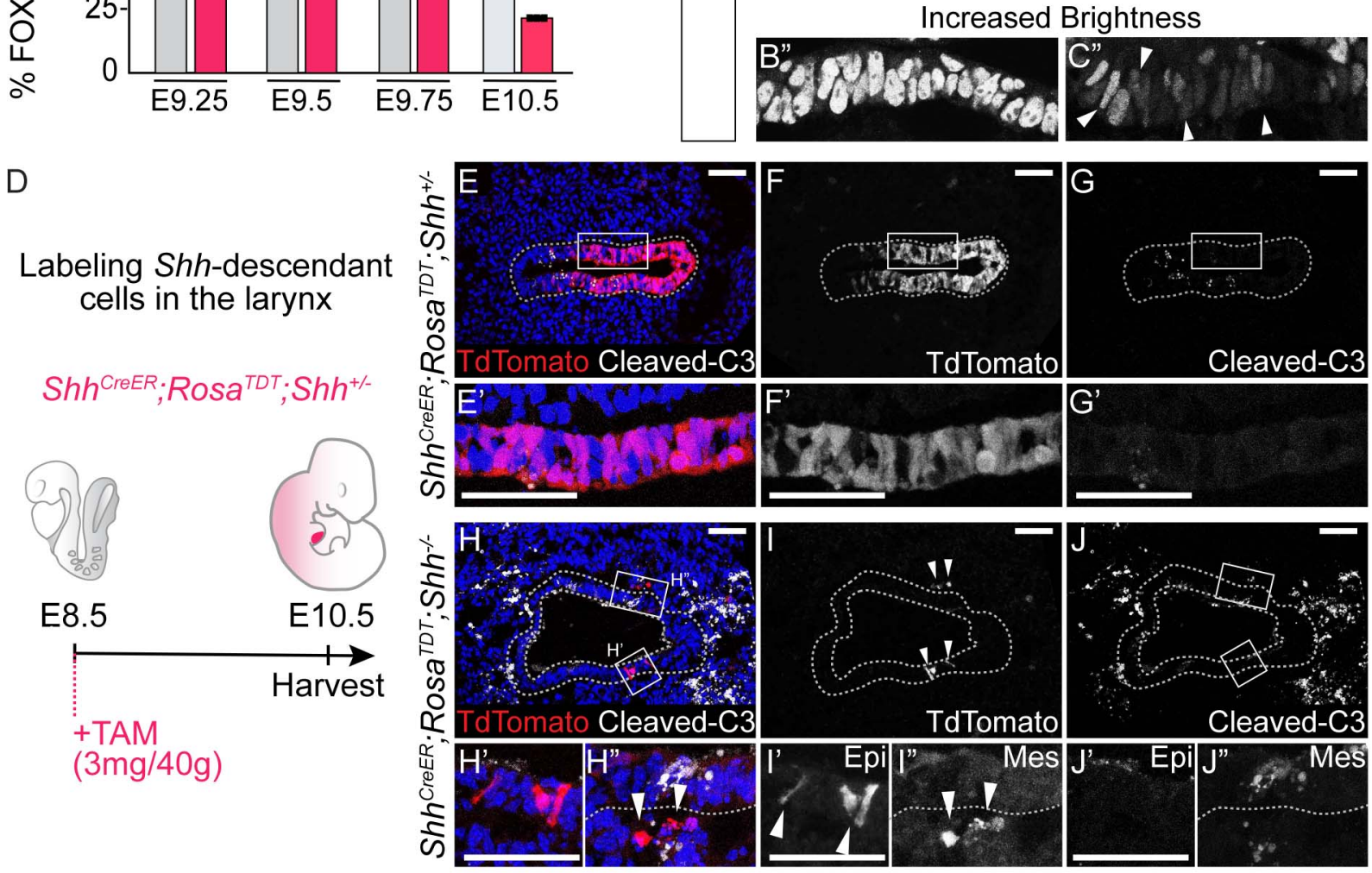

K TDT+ mesenchymal cells

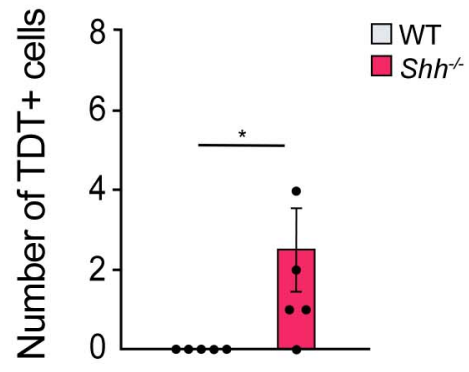

L TDT+ epithelial cells

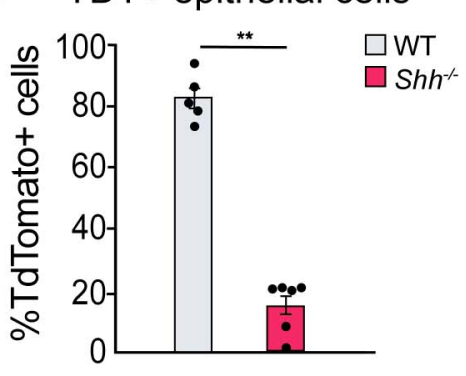

Figure 4. Epithelial cells lose FOXA2 and leave the epithelium in the absence of HH signaling. A. FOXA2 expression in control and Shh ${ }^{-/}$larynxes at E9.25 (21-23s), E9.5 (24-26s), E9.75 (27-29s) and E10.5 (32-35s). The percentage of epithelial cells expressing FOXA2 in 3 control and $3 \mathrm{Shh}^{-/}$larynxes was averaged at each developmental stage and analyzed for significance using a Student's t-test. Error bars show the standard error of the mean. B-C. FOXA2 (green) expression is reduced in Shh ${ }^{-1} \mathrm{~s}$ by E9.75 (27-29s) compared to controls. Arrowheads indicate FOXA2-low cells (B',B"). Panels B and C have been repeated in Supplemental Figure 4 for clarity. D-J. 5 Shh CreER ;Rosa ${ }^{T D T} ; \mathrm{Shh}^{+/-}(\mathrm{E}-\mathrm{G})$ and $5 \mathrm{Shh}^{\text {CreER}}$;Rosa ${ }^{T D T} ; \mathrm{Shh}^{-/}(\mathrm{H}-\mathrm{J})$ embryos were induced with Tamoxifen at E8.5 and analyzed for TD-Tomato (TDT) expressing Shh-descendant cells (in red; E-F, H-I) and for Cleaved-Caspase3 expression (in white; E, G,H,J) in the larynx at E10.5. Arrowheads indicate Shh-descendant cells within the epithelium (I') and within the mesenchyme (H",l"). K. The number of TDT-expressing cells found in the mesenchyme in 5 controls and $5 \mathrm{Shh}^{-/ s}$ was quantified and tested for significance using the Student's t-test. Error bars show the standard error of the mean. L. The percentage of TDT-expressing cells within the ventral half of the epithelium in 5 controls and 5 $\mathrm{Shh}^{-/ \mathrm{s}}$ was quantified and tested for significance using the Student's t-test. Error bars show the standard error of the mean. ${ }^{*} p<0.05^{* *} p<0.005^{* * *} p<0.0005$; n.s.-not significant. All scale bars denote $50 \mu \mathrm{m}$. 


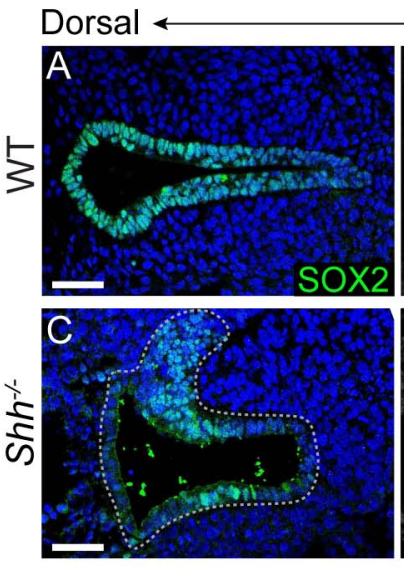

F Up-regulated larynx genes among unique endoderm markers at E9.5
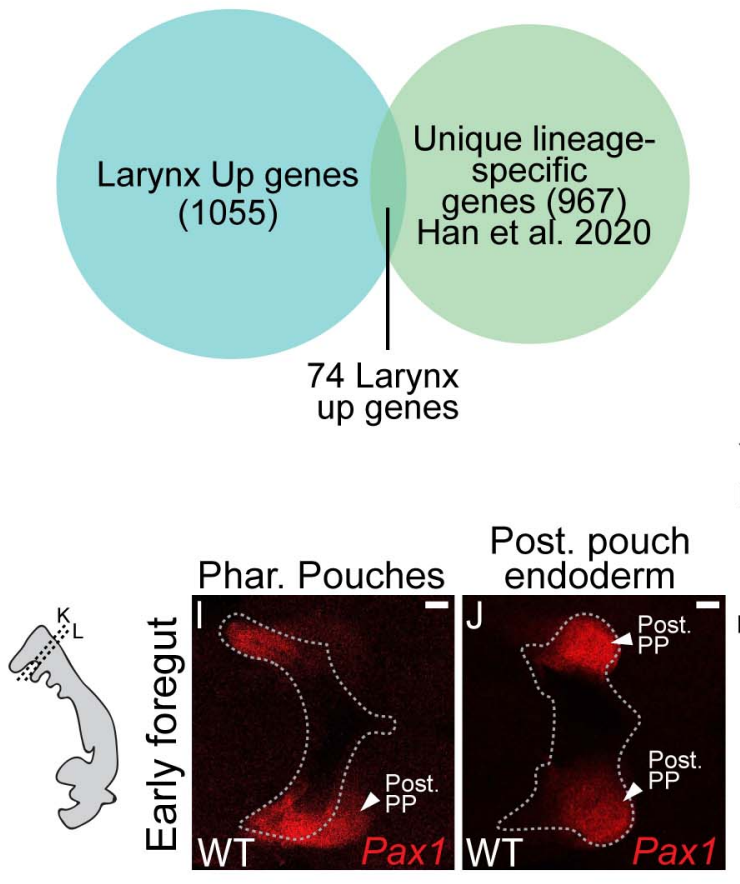

$\mathrm{H}$

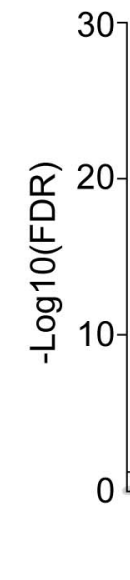
Ventral
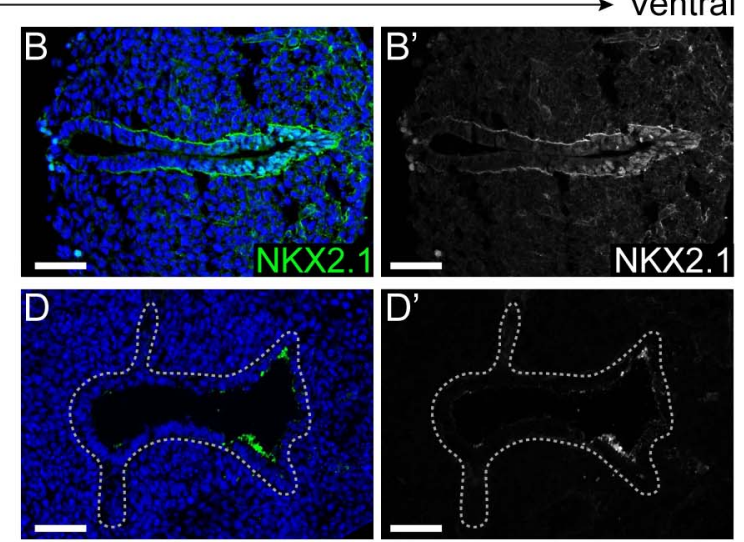

\section{E Expression of SOX2} and NKX2.1
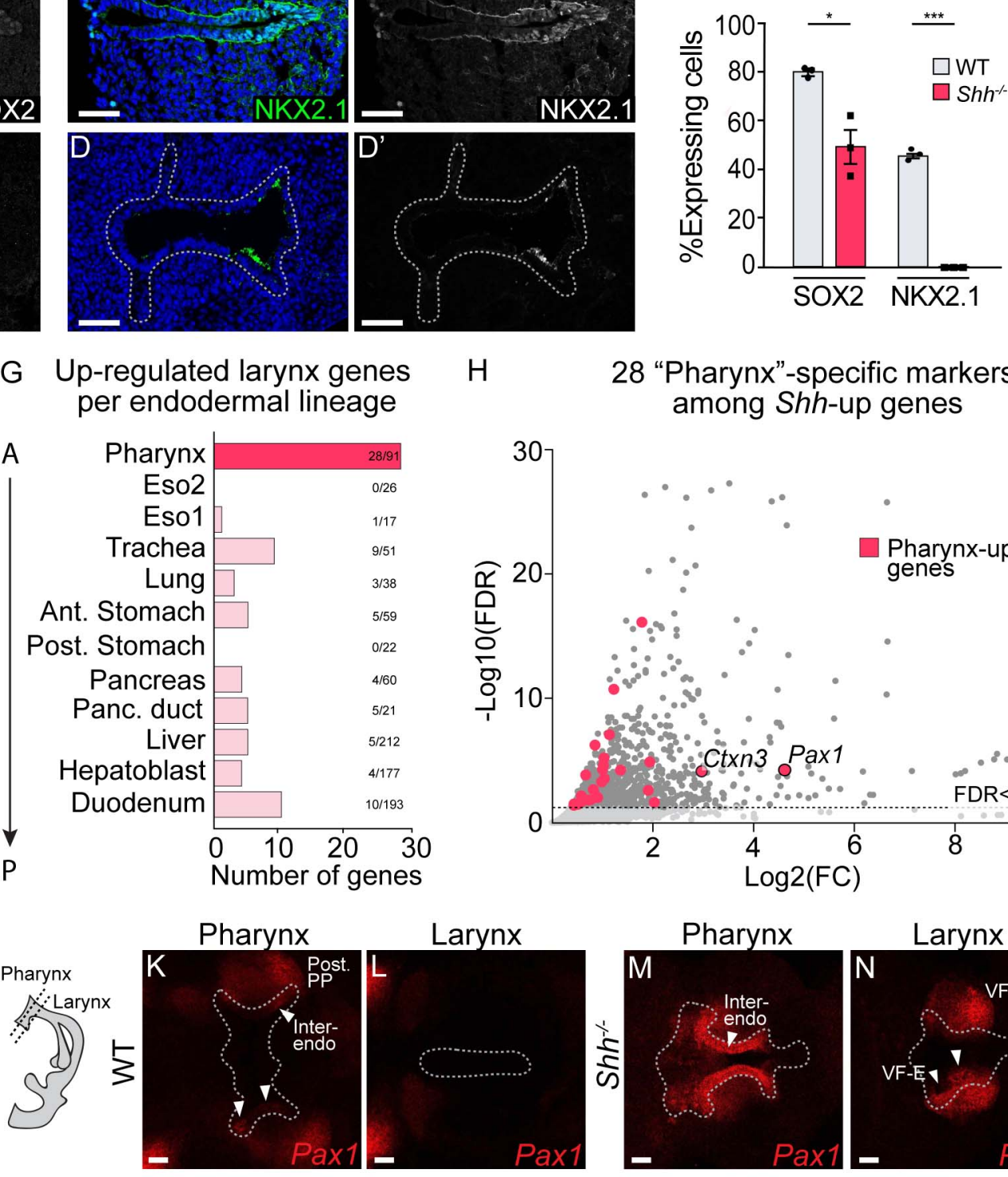

28 "Pharynx"-specific markers among Shh-up genes

G Up-regulated larynx genes per endodermal lineage

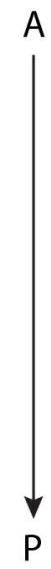

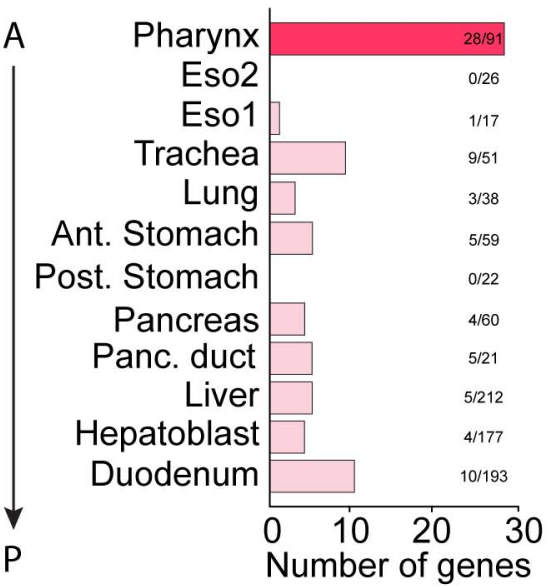

Larynx
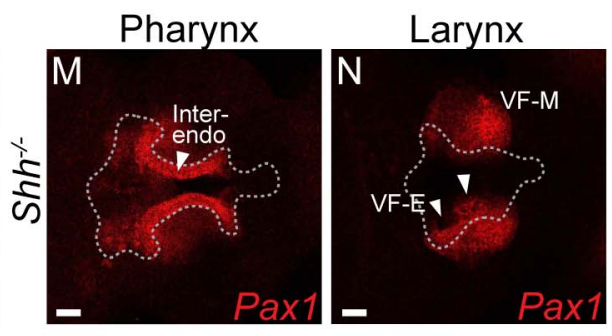

Figure 5. Shh-descendant larynx epithelial cells are replaced by an ectopic population of Pax1-expressing cells in the absence of HH signaling. A-E. SOX2 (A,C) and NKX2.1 (B-D) expression in 3 control and Shh'larynxes at E10.5 ( $n=3$ per genotype). E. The percentage of SOX2 and NKX2.1-expressing cells within the epithelium was quantified in 3 controls and $3 \mathrm{Shh}^{-/}$s each at E10.5 and analyzed for significance using the Student's t-test $\left({ }^{*} p<0.05^{* * *} p<0.0005\right)$. Error bars plot the standard error of the mean. F. Endodermal genes identified by Han et al. 2020 were used to infer the composition of the epithelium in Shh- embryos. Up-regulated genes within the Shh ${ }^{-1}$ RNA-seq dataset (1056) were intersected with lineage specific endodermal genes (968) identified at E9.5 (Han et al., 2020) resulting in 74 annotated endodermal genes that were up-regulated in the absence of $\mathrm{HH}$ signaling. $\mathrm{G}$. Lineage-specific categorization of the 74 up-regulated genes in the larynx showed that pharynx-specific genes $(28 / 74)$ are enriched within this group. $H$. The expression levels of the 28 pharynx-specific genes (pink) among all upregulated genes within Shh ${ }^{-/}$larynxes (grey). The dashed line denotes the FDR cutoff <0.05. I-J. Pax1 (red) expression within the pharyngeal pouches in control E9.5 foregut tissues $(n=3)$. K-N. Pax1 (red) expression within the pharynx and larynx of control (K-L) and $S h h^{--}(M-N)$ embryos at E10.5 ( $n=3$ for each genotype). Post. PP-posterior pharyngeal pouch; Inter-endo.-inter-pouch endoderm; VF-M-vocal fold mesenchyme; VF-E-vocal fold epithelium. All scale bars denote $50 \mu \mathrm{m}$. For the list of genes used for this intersection refer to Supplemental Data Table 2. 
A Epithelial cells undergo EMT and cell death and are replaced by different populations

Down-regulation of E-Cad

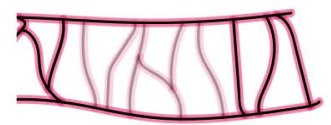

Co-expression of E-Cad/N-Cad

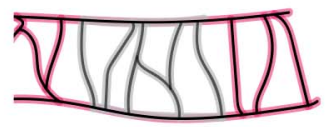

$\mathbb{N}$-Cad-expressing cells undergo extrusion and cell death

Pax1-expressing cells

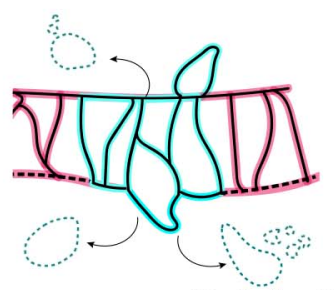

Cell death

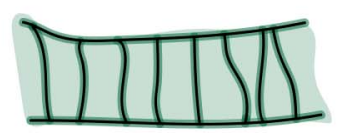

$+\mathrm{HH}$

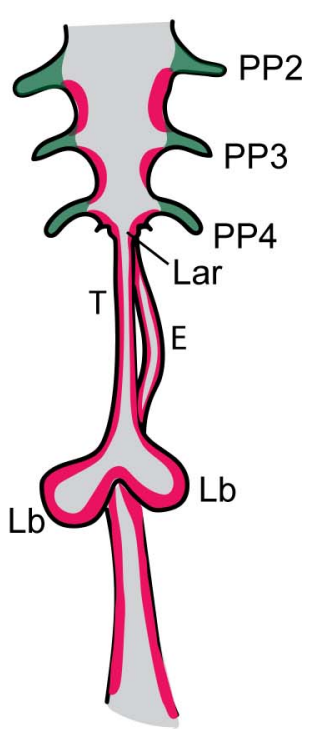

FOXA2 Pax1

B

Model for HH-regulated remodeling by EMT in the larynx

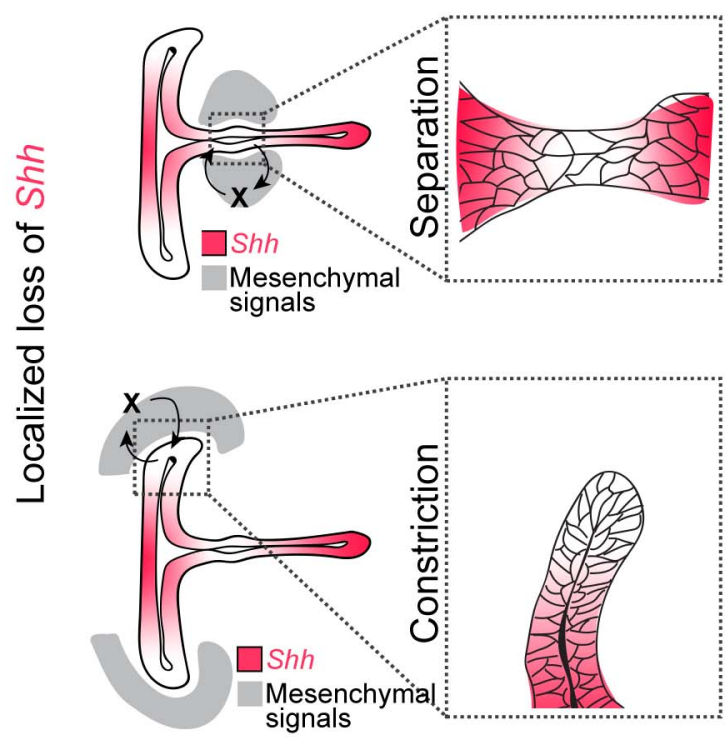

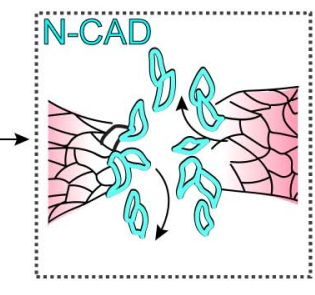

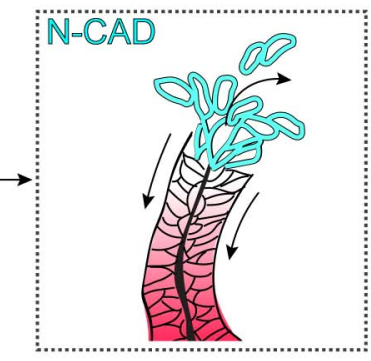

$-\mathrm{HH}$

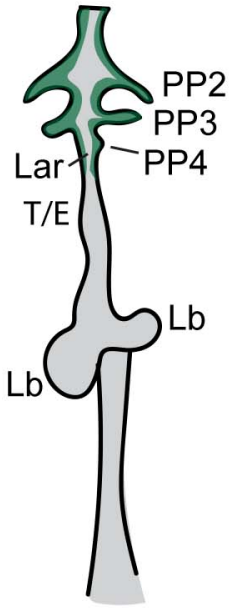

Figure 6. Dynamic HH signaling drives the homeostasis of the early anterior foregut endoderm and may also regulate later stages of larynx remodeling. A. Epithelial cells marked by E-Cadherin and FOXA2 (pink) in the anterior foregut undergo EMT (marked by N-Cadherin expression in cyan), migrate out of the foregut epithelium, and undergo cell death in the absence of $\mathrm{HH}$ signaling. These cells are then replaced by different Pax1-expressing (dark green) populations. B. We hypothesize that dynamic SHH (pink) expression within the larynx epithelium drives EMT-mediated morphogenesis are later stages of larynx development, specifically larynx-esophageal separation and esophageal constriction. PP 2/3/4-Pharyngeal pouches \#2-4, Lar-larynx, T-trachea, E-esophagus, Lb-lung buds. 


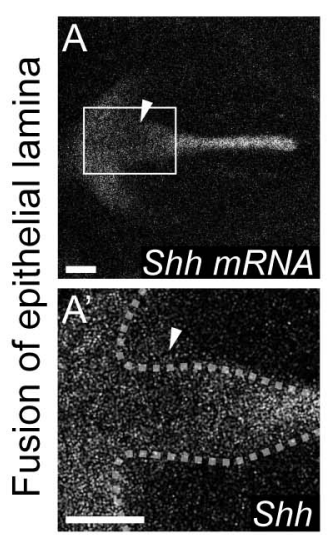

B Shh in epithelial lamina

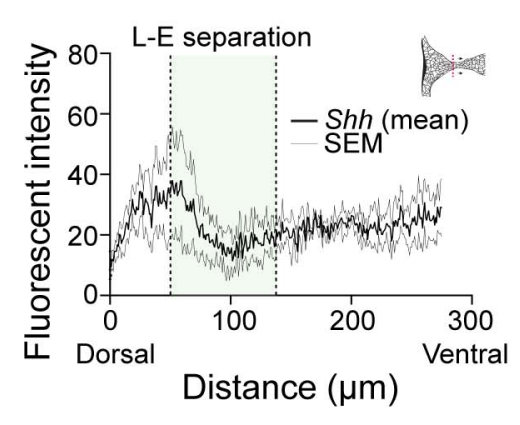

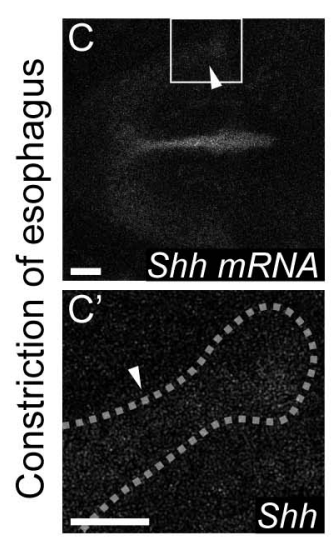

D

Shh in esophageal epithelium

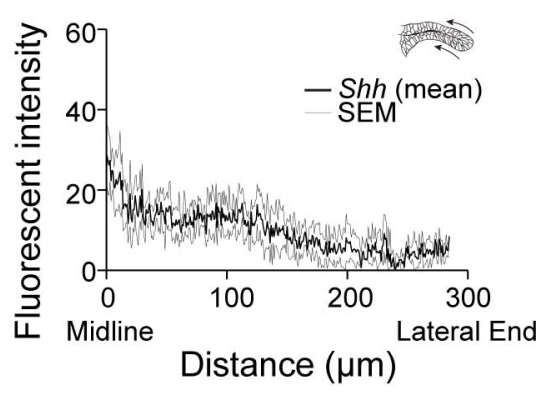

Esophageal epithelium
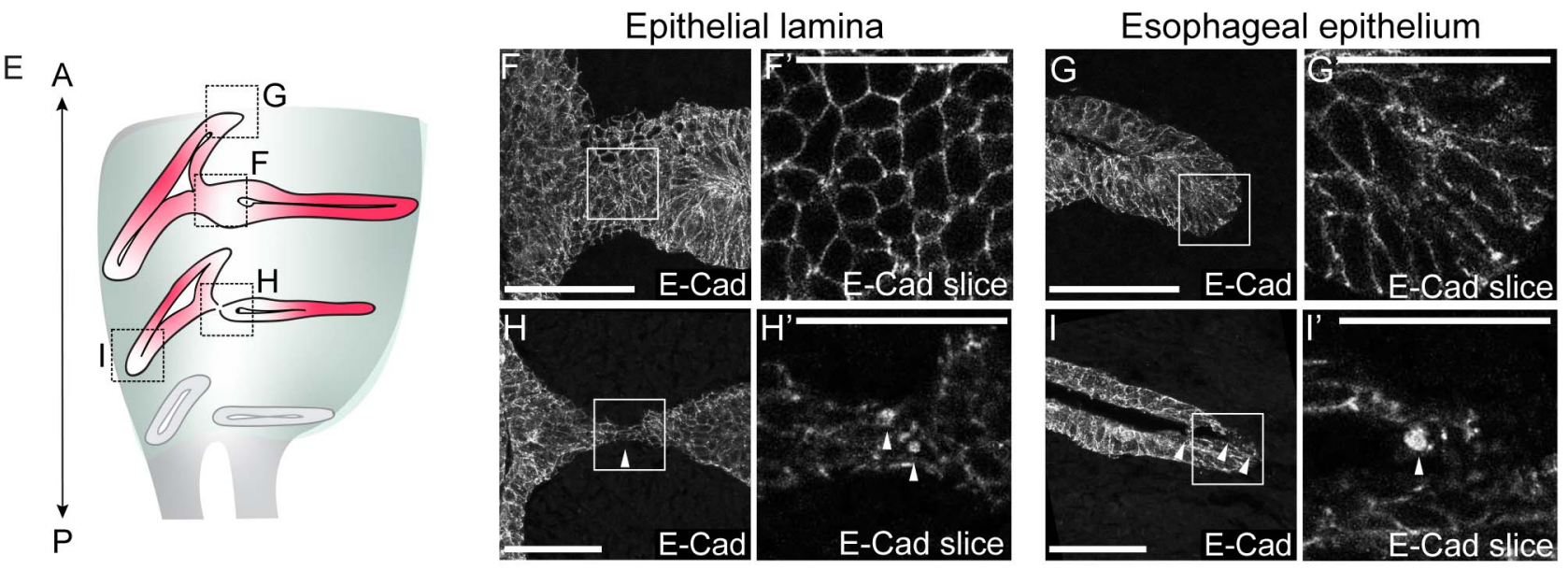

Figure 1-figure supplement 1. Shh expression is reduced, and E-Cadherin is re-localized in the epithelial lamina and the constricting esophagus during larynx-esophageal separation. A-D. Shh expression in the epithelial lamina and the constricting esophageal opening in 3 control E11.75 whole-mount larynxes by fluorescent in situ-hybridization. Relative Shh (B, D) expression was measured by line scans of fluorescent intensity along the epithelial lamina (A-B) and the esophagus (C-D) in all 3 larynxes. Graphs show average fluorescent intensity and the standard error of mean across the three replicates. E. E-Cadherin protein expression in the epithelial lamina and the constricting esophagus in anterior larynx sections prior to larynx-esophageal separation (F-G), and more posteriorly at the level of larynx-esophageal separation $(\mathrm{H}-\mathrm{I})$. E-Cadherin expression and distribution across the cell surface was analyzed in 3 larynxes. H' and l'. Punctate E-Cadherin expression was observed in single slices at both regions of remodeling at the level of larynx-esophageal separation. A-anterior; P-posterior. F',G',H',I'. Scale bars denote $25 \mu \mathrm{m}$. All other scale bars denote $50 \mu \mathrm{m}$. 
A

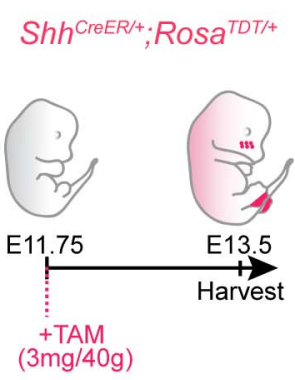

$(3 \mathrm{mg} / 40 \mathrm{~g})$
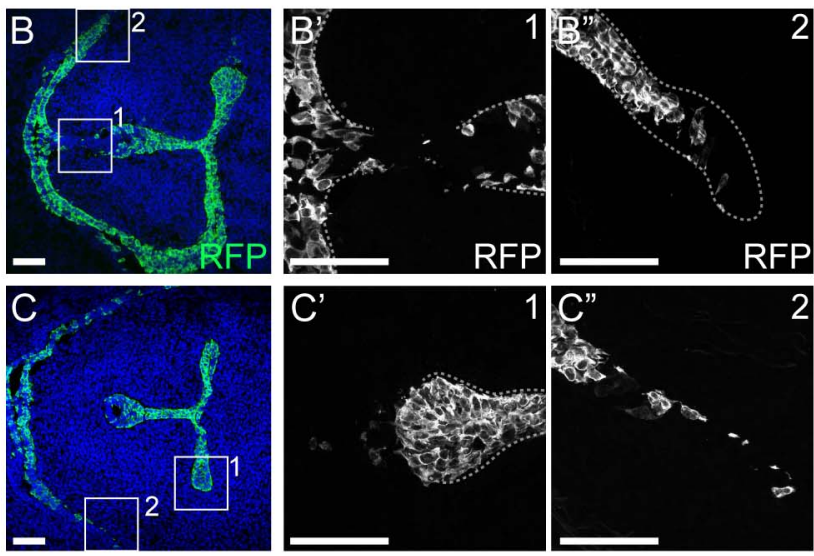

D

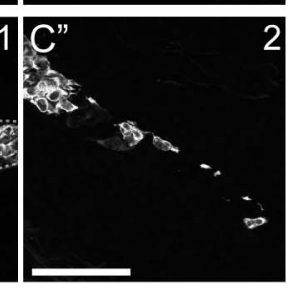

Induction of $\mathrm{N}$-Cadherin

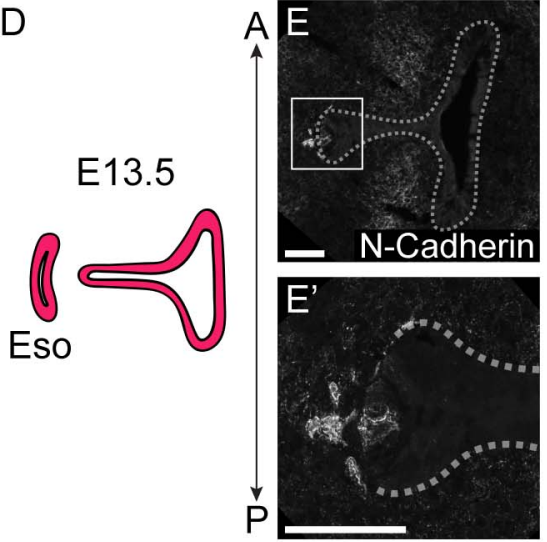

Figure 1-figure supplement 2. Shh-descendant cells express $\mathrm{N}$-Cadherin and undergo EMT during larynx-esophageal separation. A-C. Shh ${ }^{\mathrm{CrEER} /} ; \mathrm{ROSa}^{T D T / 4}$ embryos (3 replicates) were induced with Tamoxifen at E11.75 and examined for RFP (green) expression at E13.5 in anterior (B) and posterior (C) sections of the larynx. Arrowheads indicate extruding RFP-positive Shh-descendant cells in the mesenchyme. D-F. N-Cadherin expression in anterior $(E)$ and posterior $(F)$ sections through the larynx at E13.5 at the region of larynx-esophageal separation ( 3 replicates at each plane). All scale bars denote $50 \mu \mathrm{m}$. 
bioRxiv preprint doi: https://doi.org/10.1101/2022.01.19.476887; this version posted January 20,2022. The copyright holder for this preprint (which was not certified by peer review) is the author/funder, who has granted bioRxiv a license to display the preprint in perpetuity. It is made available under aCC-BY 4.0 International license.
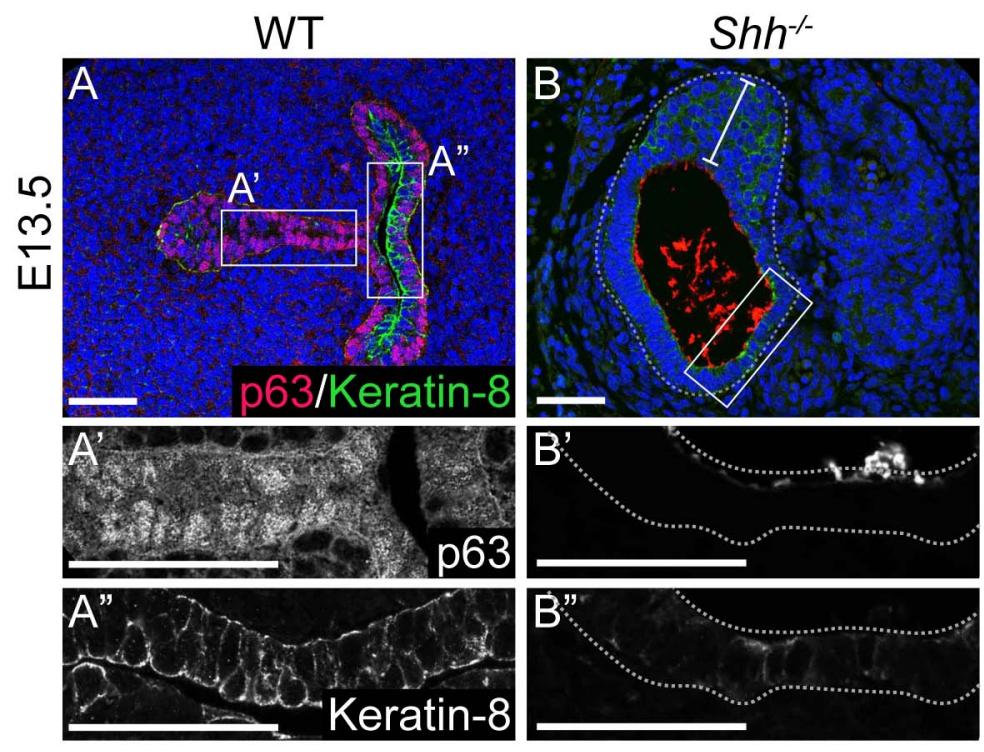

Figure 2-figure supplement 1. Loss of $\mathrm{HH}$ signaling results in the persistence of a poorly keratinized, p63-negative epithelium at late stages of larynx development. A-B. P-63 (red) and Keratin-8 (green) expression in 3 control and $3 \mathrm{Shh}^{--}$larynxes at E13.5. All scale bars denote $50 \mu \mathrm{m}$. 

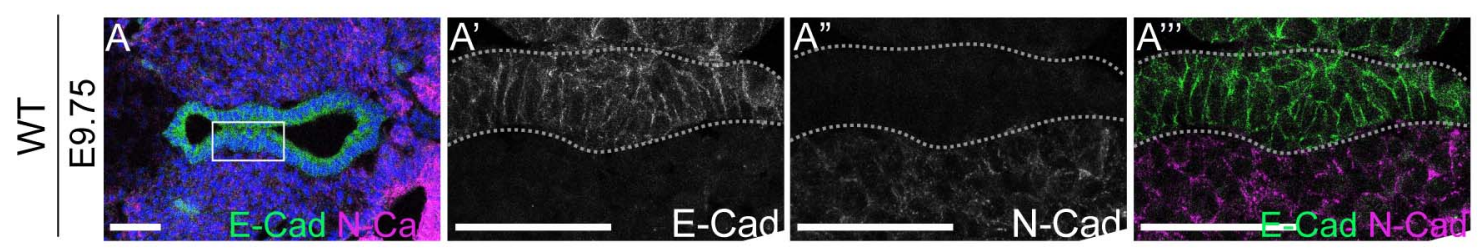

D Cadherin-switching in
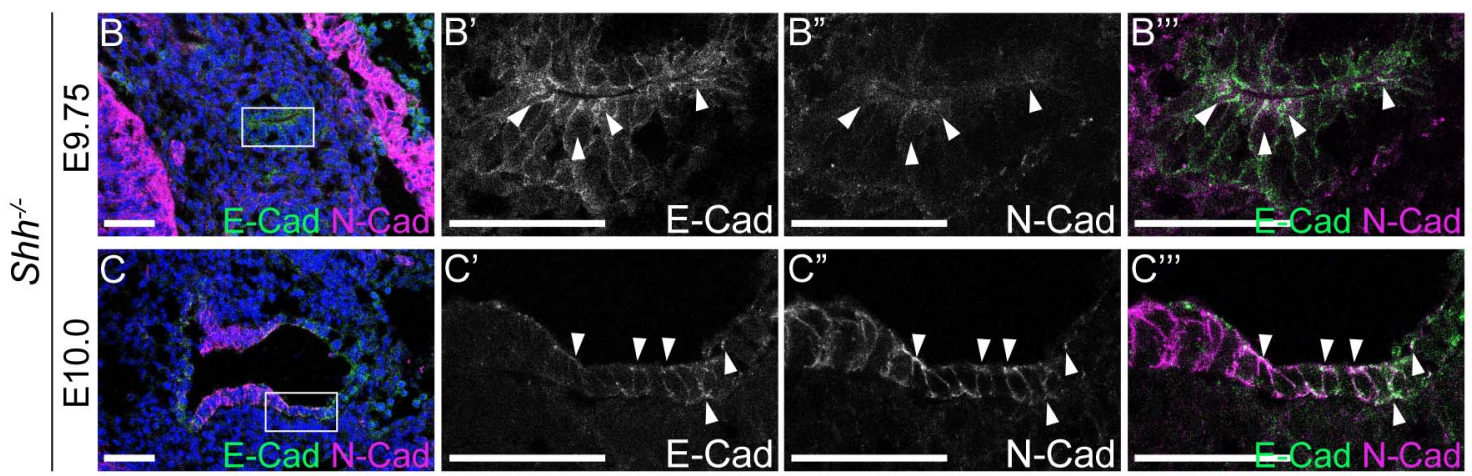
$\mathrm{Shh}^{--}$epithelia
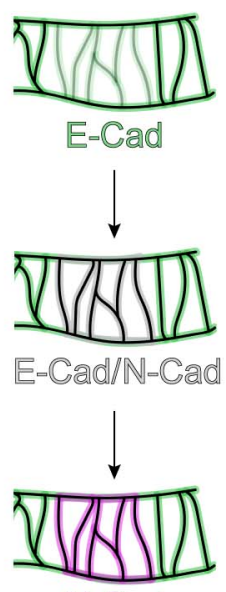

$\mathbb{N}=\mathrm{Cad}$

Figure 3-figure supplement 1. Larynx epithelial cells co-express E-Cadherin and $\mathrm{N}$-Cadherin during early stages of foregut development in the absence of $\mathrm{HH}$ signaling. A-D. E-Cadherin (green) and N-Cadherin (magenta) in the vocal fold epithelium of 3 control and $3 S^{-1-}$ embryos at E9.75 (27-28s) (A-B) and at E10.0 (29-31s) (C). White arrowheads mark regions of co-expression along the apical surface as well as along the cell boundaries. All scale bars denote $50 \mu \mathrm{m}$. 
bioRxiv preprint doi: https://doi.org/10.1101/2022.01.19.476887; this version posted January 20, 2022. The copyright holder for this preprint (which was not certified by peer review) is the author/funder, who has granted bioRxiv a license to display the preprint in perpetuity. It is made available under aCC-BY 4.0 International license.
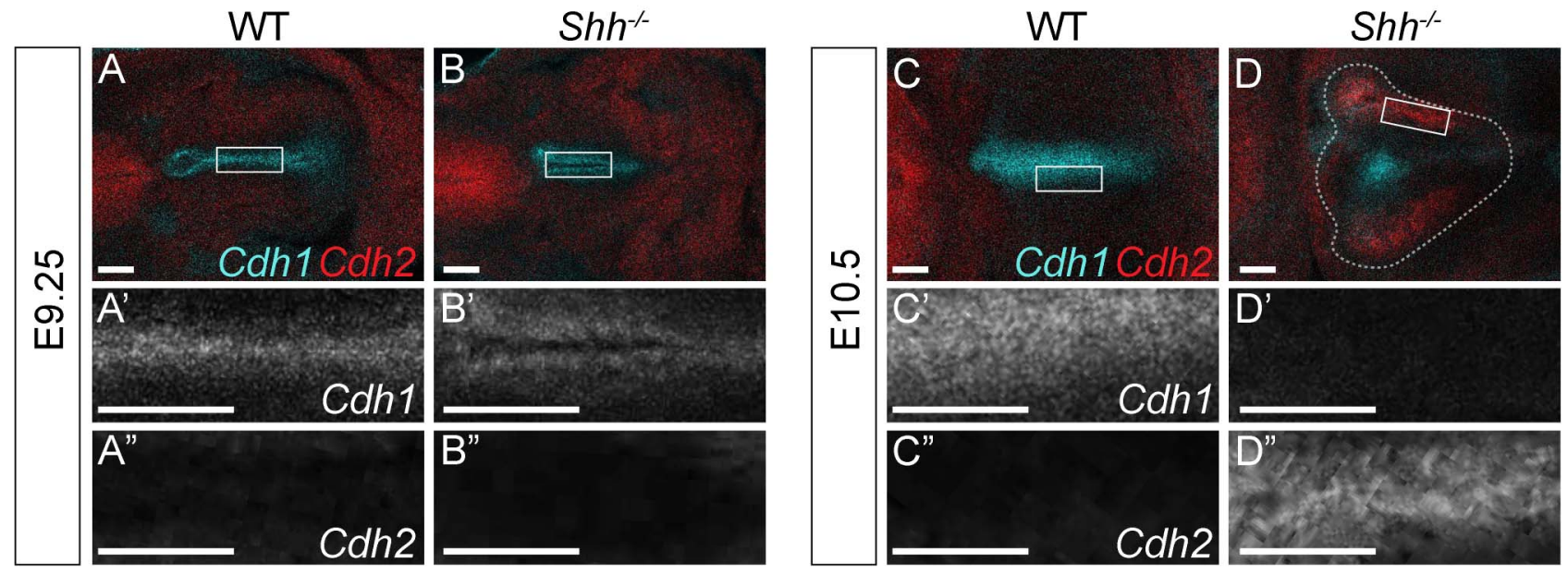

Figure3-figure supplement 2. HH is required to maintain Cdh1 expression in the early foregut. A-D. Cdh1 (cyan) and $\mathrm{Cdh} 2$ (red) expression by whole-mount fluorescent in-situ hybridization in 3 control and $3 \mathrm{Shh}^{-1}$ larynxes

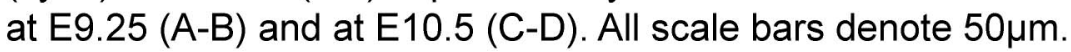



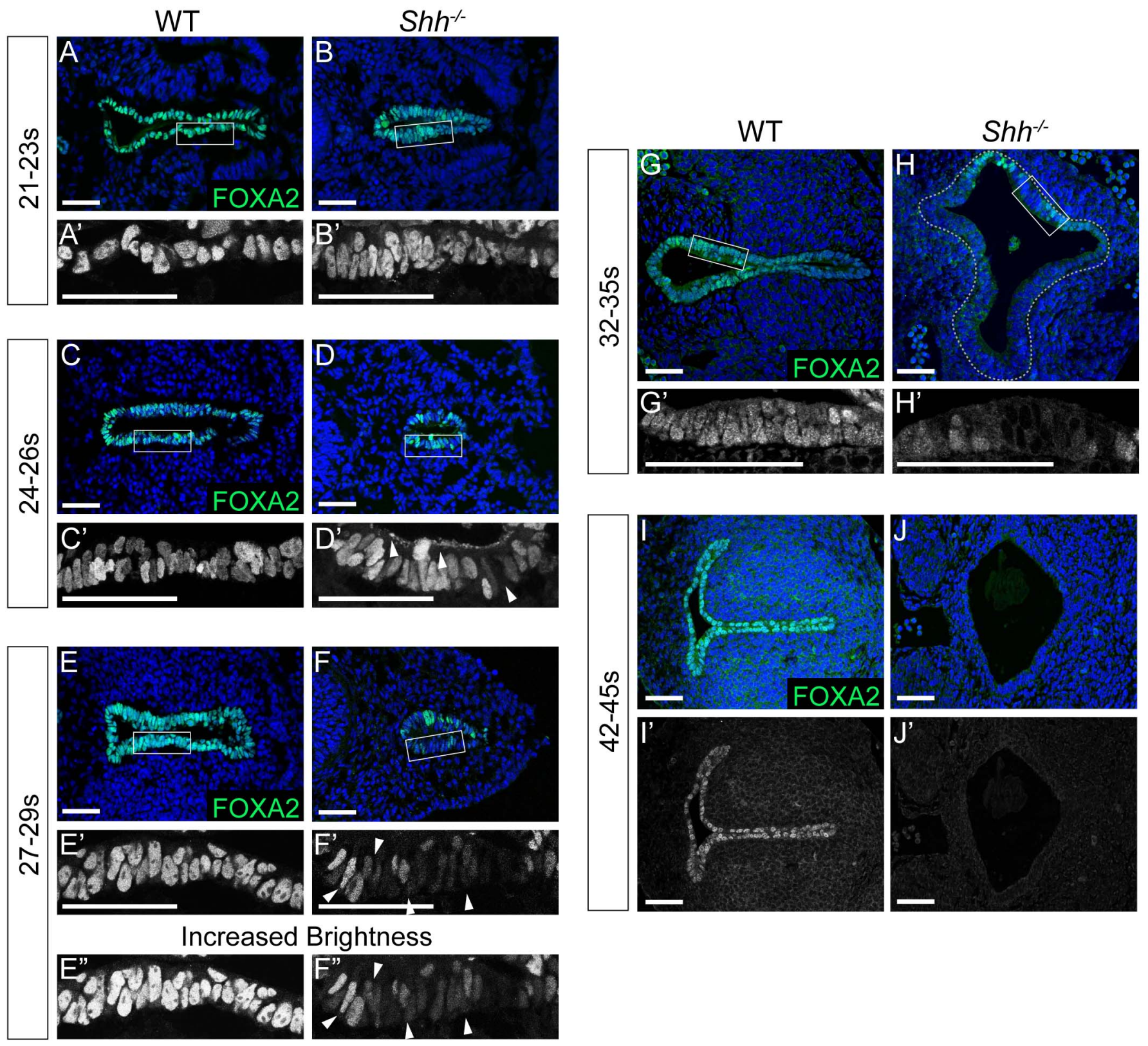

Figure 4-figure supplement 1. FOXA2 is downregulated in the early foregut endoderm and absent from the larynx epithelium by E11.5 in Shh/-s. A-J. FOXA2 expression (green) in control and Shh ${ }^{-/}$larynxes at E9.25 (21-23s, A-B), E9.5 (24-26s, C-D), E9.75 (27-29s, E-F), E10.5 (32-35s, G-H), and E11.5 (42-45s, I-J). 3 controls and 3 mutants were examined at each timepoint. Panels $E$ and $F$ have been repeated here from Figure 3 for clarity. All scale bars denote $50 \mu \mathrm{m}$. 

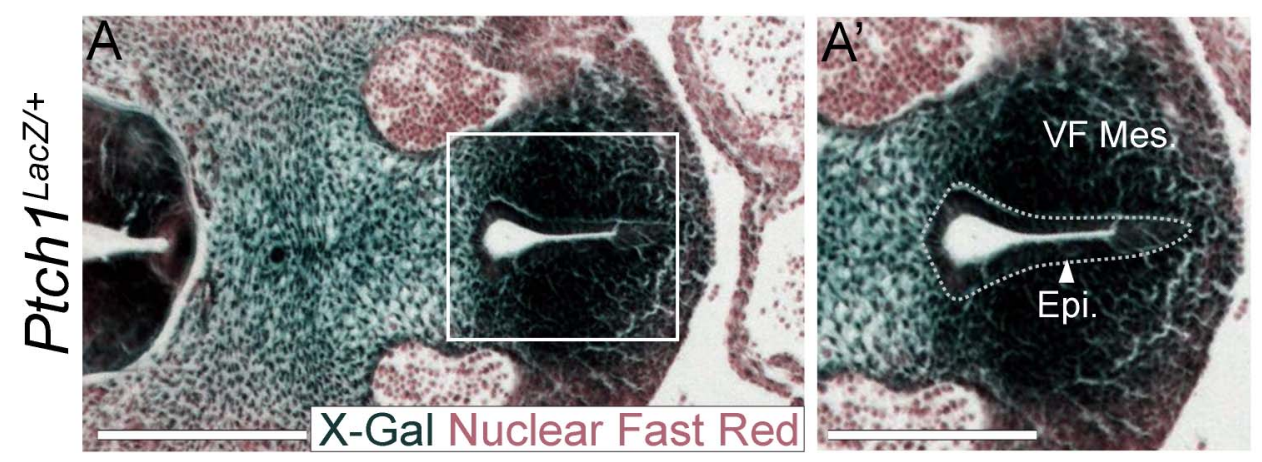

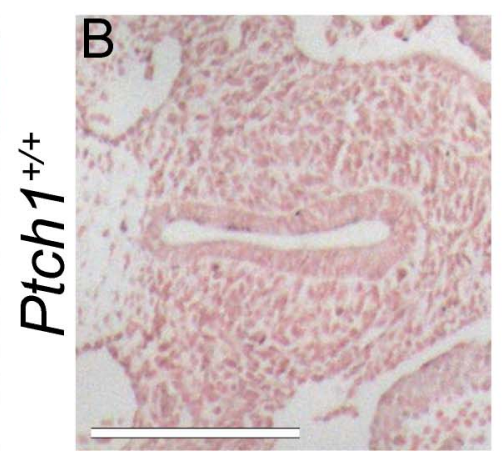

Increased Brightness
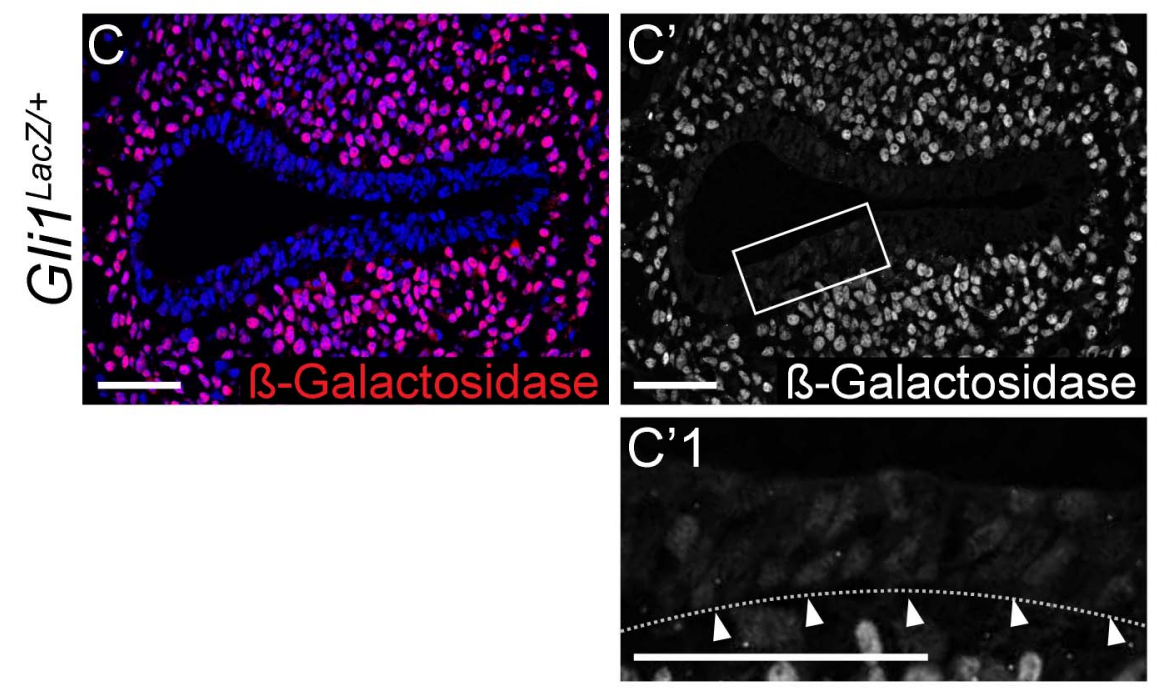

Figure 4-figure supplement 2. Ptch $h^{L a c z}$ and Gli1 ${ }^{L a c z}$ expression is present within the larynx epithelium as well as the mesenchyme at E10.5. A-A'. Ptch ${ }^{\text {LacZ }}$ expression by B-galactosidase (marked by X-Gal in dark blue) staining of $3 \mathrm{Ptch}^{\mathrm{LacZ} /+}$ embryos at E10.5. Embryos were fixed in $1 \%$ formaldehyde $/ 0.2 \%$ glutaraldehyde, stained in $1 \mathrm{mg} / \mathrm{ml}$ X-gal for 4 hours and sectioned to generate $5 \mu \mathrm{m}$ sections that were then counterstained with Nuclear Fast Red. B. Sections through the larynx from control $\left(P t c h^{+/}\right)$embryos stained for ß-galactosidase and Nuclear Fast Red. A-B. Scale bars denote $250 \mu \mathrm{m}$. C-C". Gli1 LacZ expression within the larynx epithelium and mesenchyme of 3 Gli1'LacZ+

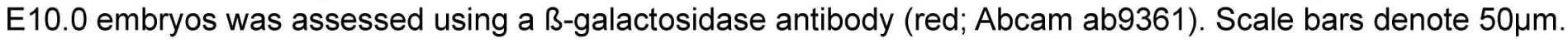



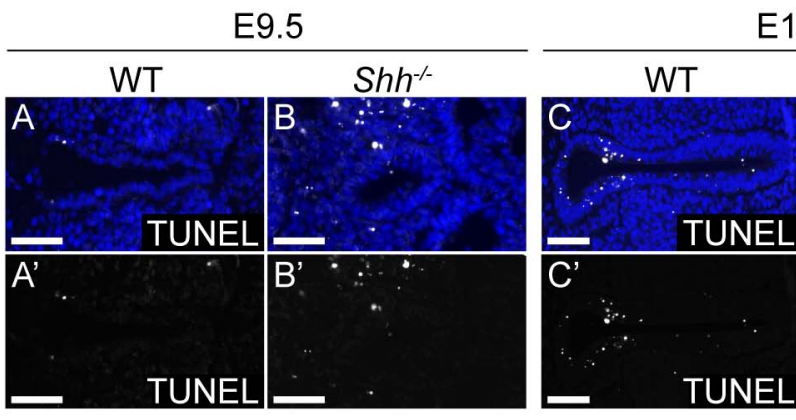

E10.5

E11.5
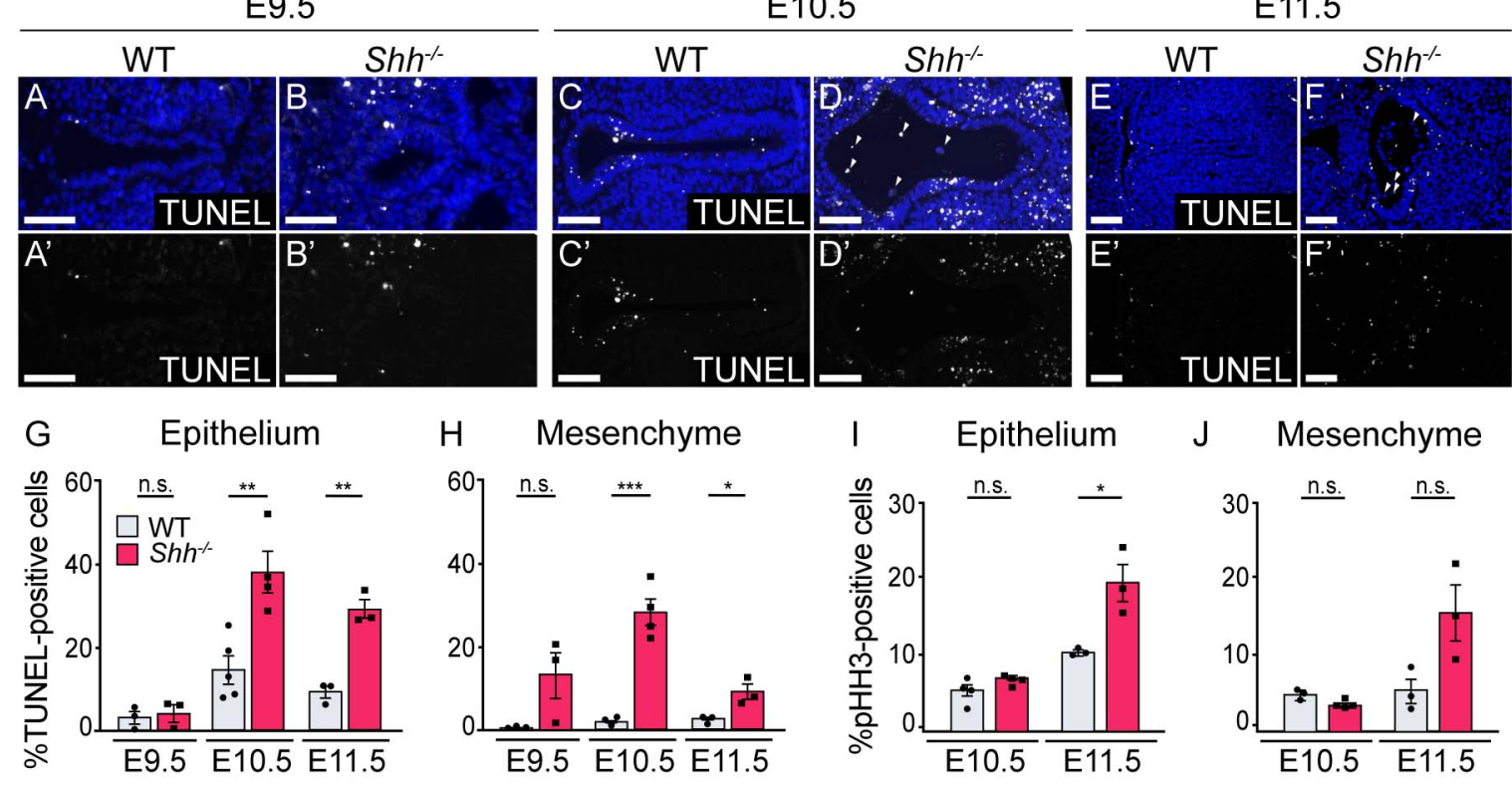

I Epithelium J Mesenchyme
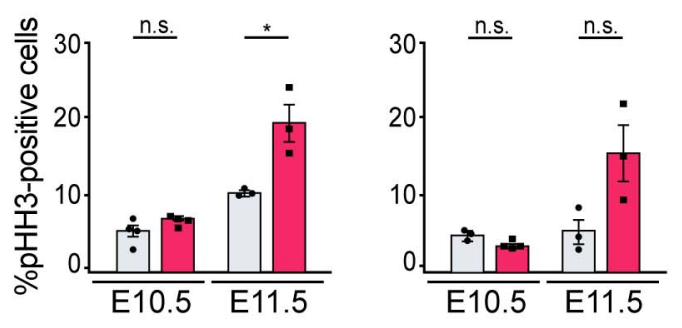

Figure 4-figure supplement 3. HH signaling is required for the survival of epithelial and mesenchymal cells within the larynx. A-F. TUNEL-staining of control and Shh-s at E9.5 (A-B), 10.5 (C-D) and E11.5 (E-F) within the epithelium and mesenchyme of the vocal folds. G-H. The percentage of TUNEL-positive cells within the epithelium and mesenchyme was quantified over 3-5 replicates each at E9.5, 10.5 and 11.5. I-J. The percentage of proliferative pHH3-positive cells within the epithelium and mesenchyme in controls and Shh ${ }^{-}$s was quantified over 3-5 replicates at E10.5, and E11.5. Average counts were analyzed for significance using a Student's t-test, and error bars denote the standard error of mean. ${ }^{*} p<0.05^{* *} p<0.005^{* * *} p<0.0005$; n.s.-not significant. All scale bars denote $50 \mu \mathrm{m}$. 

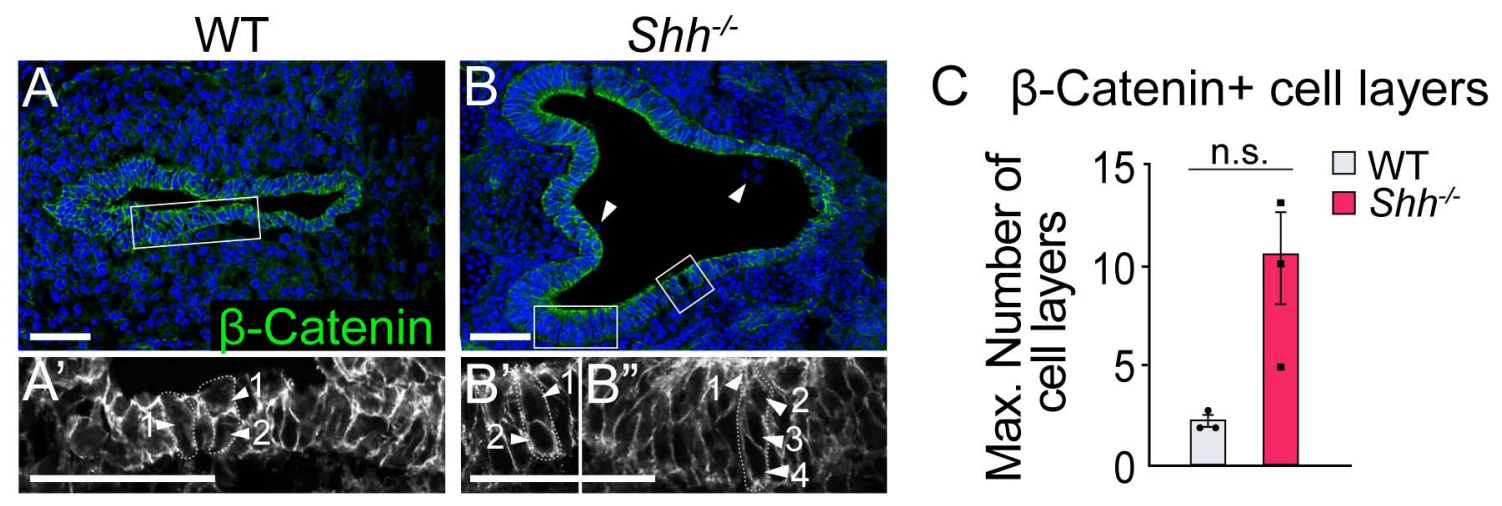

Figure 4-figure supplement 4. Loss of Shh results in a thickening and cell disorganization of the epithelial layer. A-C. $\beta$-Catenin expression (green) marks the cell layers within the epithelium. C. The number of cell layers was averaged across 3 controls and $3 S^{-/} h^{-s}$ and analyzed using a Student's t-test (n.s.-not significant). Error bars show the standard error of the mean. B. Arrowheads mark extruded cells within the lumen. B'-B". Arrowheads mark cell layers within two regions of the epithelium. All scale bars denote $50 \mu \mathrm{m}$. 
bioRxiv preprint doi: https://doi.org/10.1101/2022.01.19.476887; this version posted January 20, 2022. The copyright holder for this preprint (which was not certified by peer review) is the author/funder, who has granted bioRxiv a license to display the preprint in perpetuity. It is made available under aCC-BY 4.0 International license.

WT

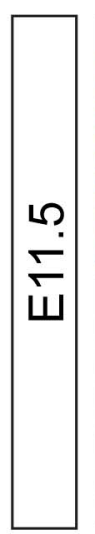

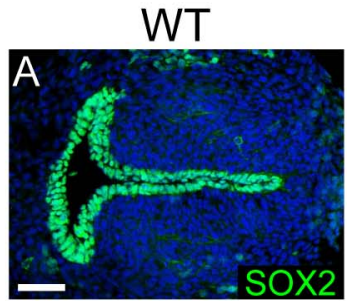
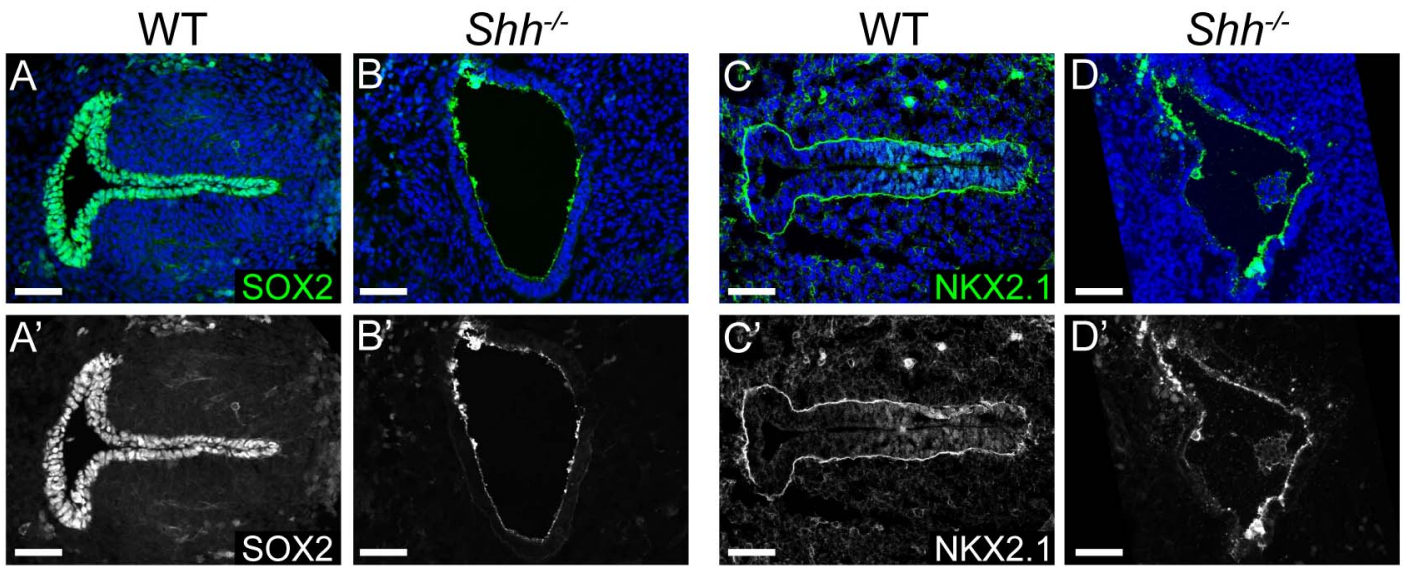

Figure 5-figure supplement 1. SOX2, and NKX2.1 are absent from the larynx epithelium by E11.5 in Shhrs. A-D. SOX2 (green; A-B) and NKX2.1 (green; C-D) expression within the epithelium of 3 control and $3 \mathrm{Shh}^{-1} \mathrm{~s}$ at E11.5. All scale bars denote $50 \mu \mathrm{m}$. 


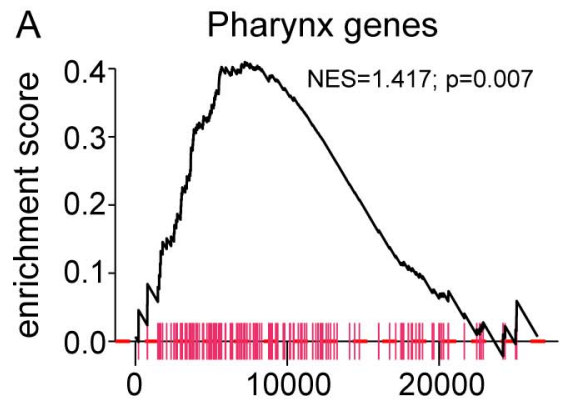

B Trachea/esophagus genes

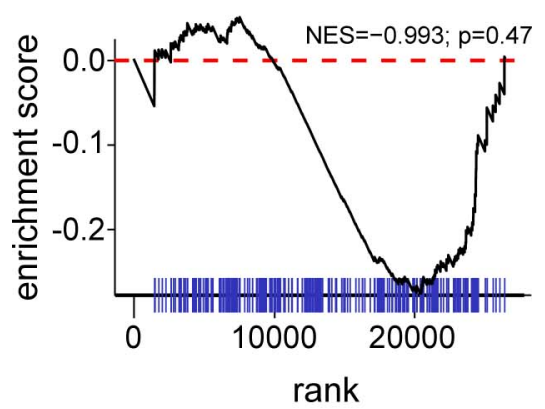

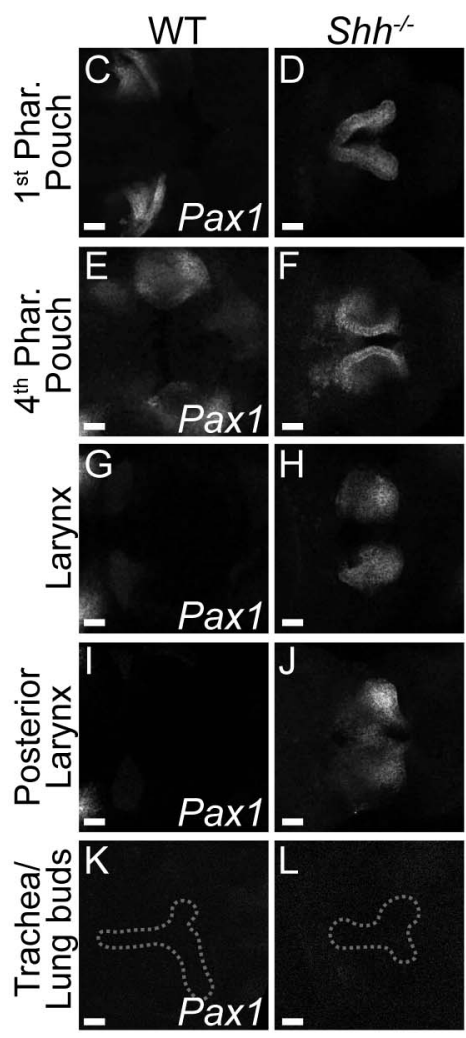

E10.5
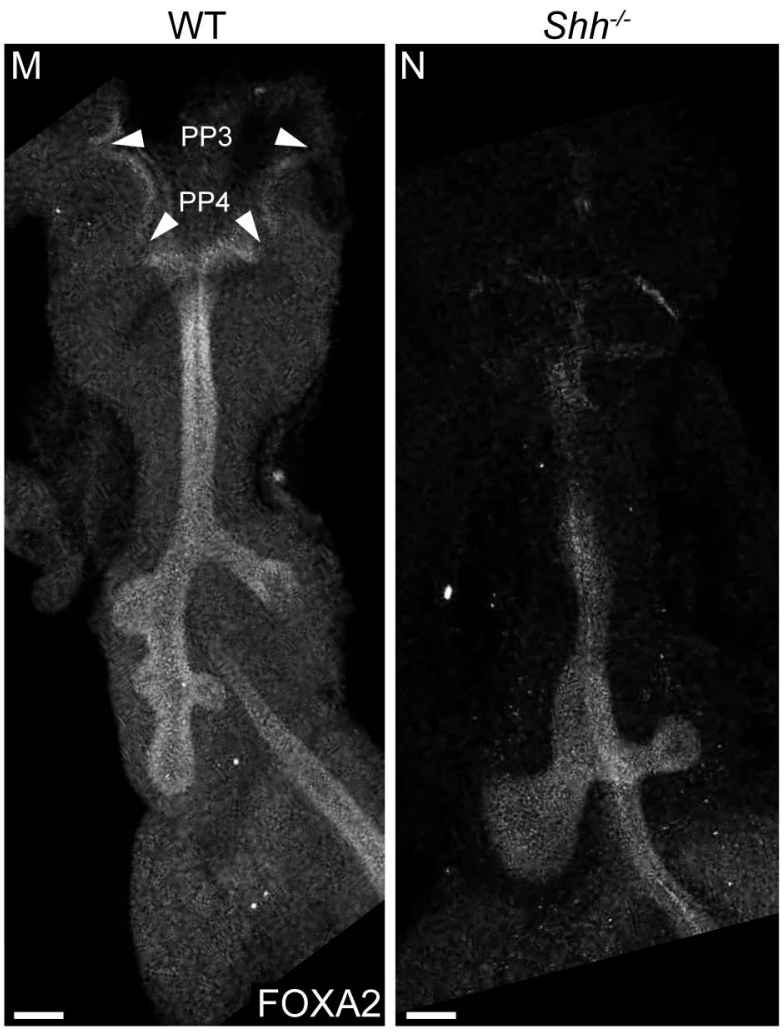

E11.5

Figure 5-figure supplement 2. Pharynx genes are enriched while FOXA2 is lost from the anterior foregut in the absence of HH signaling. A-B. Gene-set enrichment analysis on all differentially expressed genes in $S h h^{-1-}$ larynxes (Supplemental Data Table 1) against E9.5 pharynx ( $A$, pink) and tracheal/esophageal ( $B$, blue) endodermal genes identified by Han et al., 2020. Graphs were generated using the fgsea R package and $p$-values were obtained using a permutation test. C-L. Wholemount Pax1 expression along the anterior-posterior axis of foregut epithelium in 3 control and $3 \mathrm{Shh}^{--}$embryos at E10.5. Images were taken along a transverse plane. M-N. Sagittal view of wholemount FOXA2 expression along the anterior foregut in E11.5 control (3 replicates) and $\mathrm{Shh}^{-1}$ ( 3 replicates) embryos. NES-normalized enrichment score; PP3 and PP4 denote the 3rd and 4th pharyngeal pouches. All scale bars denote $50 \mu \mathrm{m}$. 